\title{
A Novel and Efficient Synthesis of Bicyclo[2.2.2]octenones and Sigmatropic shifts in Ground and Excited states: Stereoselective Route to cis-Decalins and Diquinane Frameworks
}

Vishwakarma Singh, ${ }^{* a}$ Sridhar R. Iyer" and Shaikh M. Mobin ${ }^{\mathrm{b}}$

${ }^{a}$ Department of Chemistry, National Single Crystal X-ray Diffraction Facility, Indian Institute of Technology, Bombay, Mumbai 400076 (India)

e-mail: vks@chem.iitb.ac.in

\section{Contents:}

General procedure for the preparation of $\mathrm{AgNO}_{3}$ impregnated silica gel $\quad \mathrm{S} 2$

${ }^{13} \mathrm{C}$ NMR spectra of compounds 12a-c, 15, 17, 19, 20, 22, 24, 25-28, $30,13 \mathrm{a}-\mathrm{c}, 16,31-40$ and $\mathrm{H}$ NMR spectra of 18,21 and 23 
General procedure for the preparation of silver nitrate impregnated silica gel Silver nitrate $\left(1 / 9^{\text {th }} \mathrm{g}\right.$ of the required amount of silica gel) was dissolved in minimum amount of distilled water and methanol (150 mL per gram of silver nitrate) was added, followed by the addition of the required amount of silica gel. The methanol was then removed on the rotary evaporator and the silica gel was activated in the oven at $120^{\circ} \mathrm{C}$ for 6 hours. 


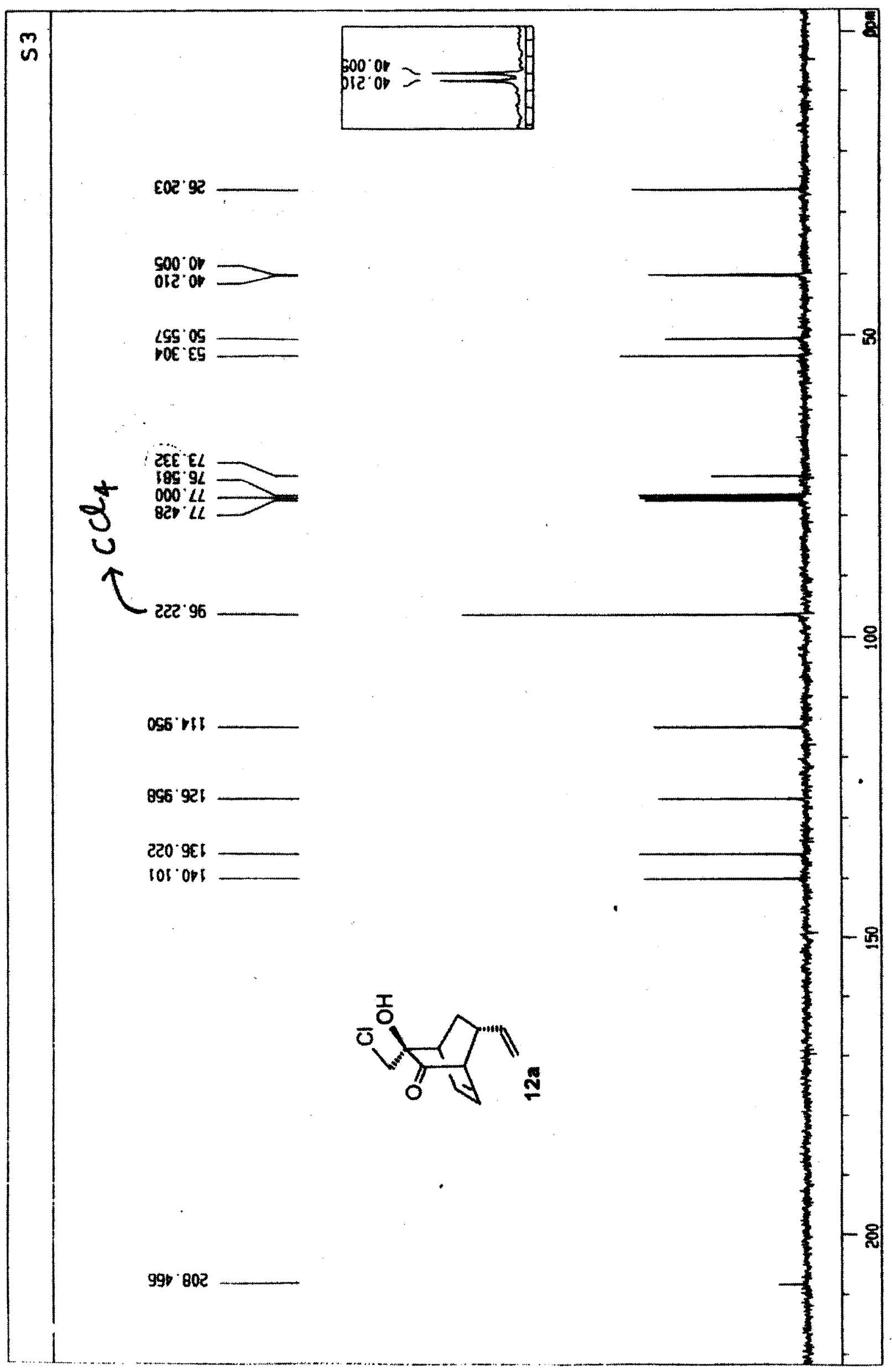




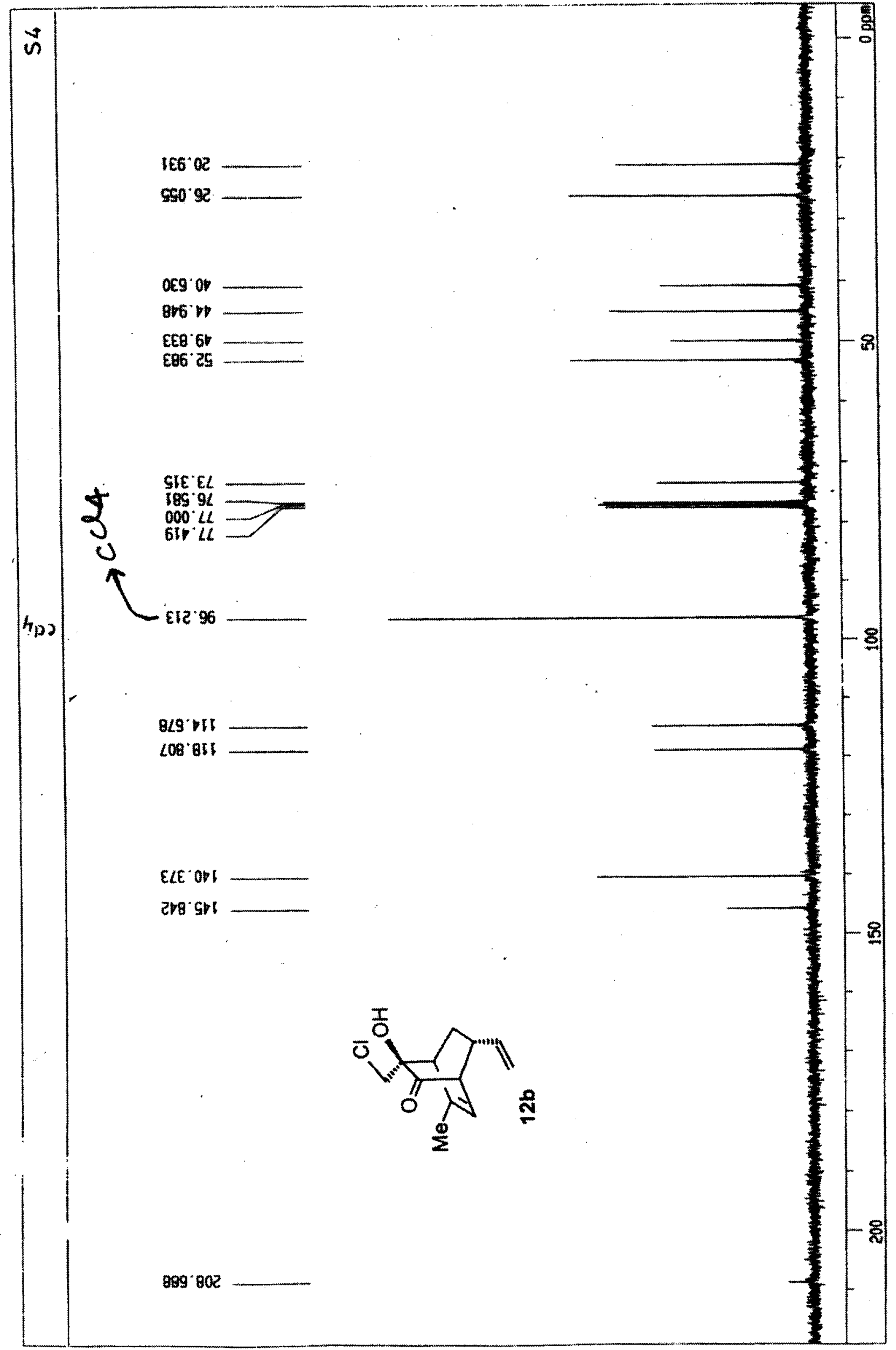




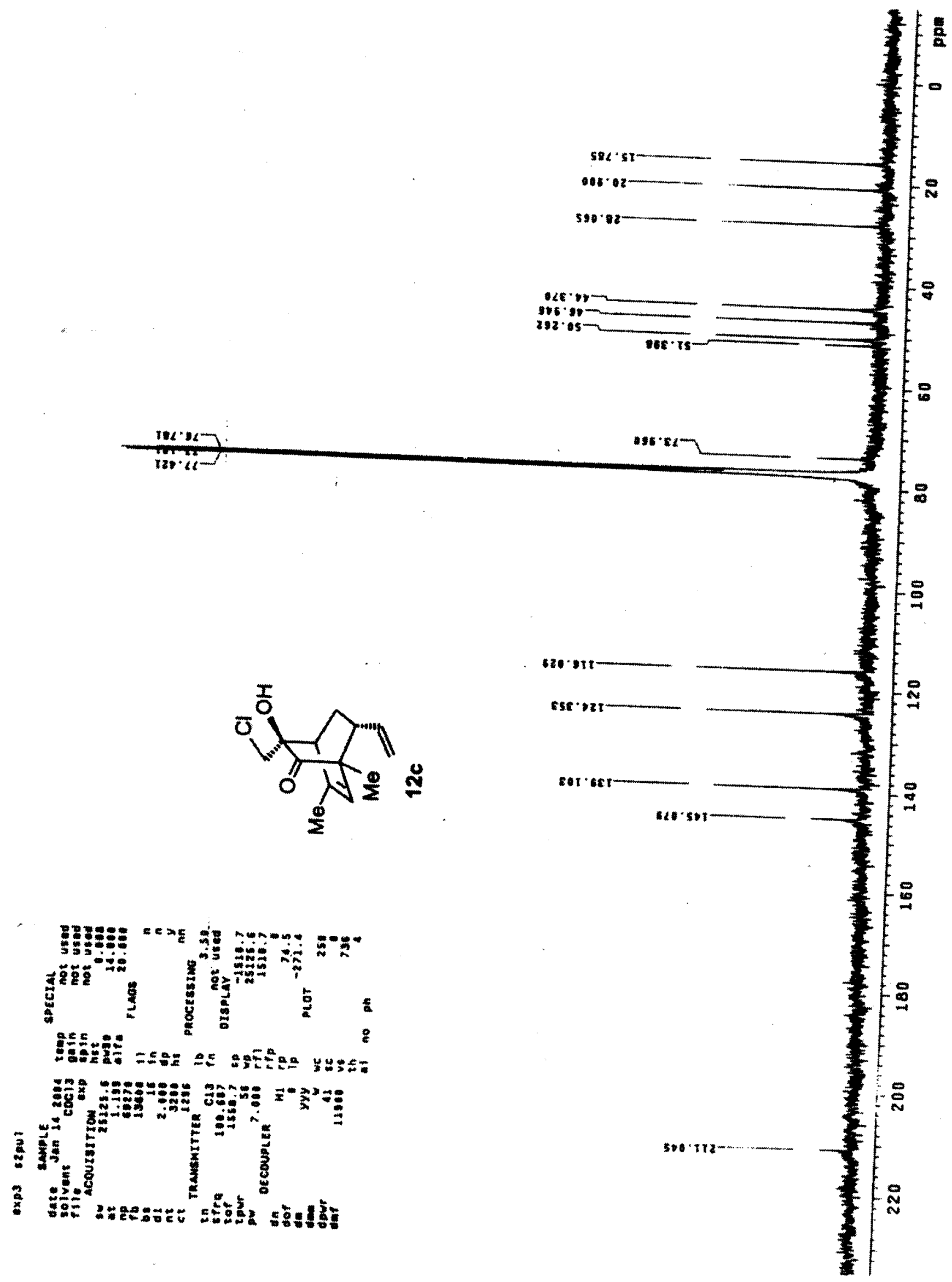




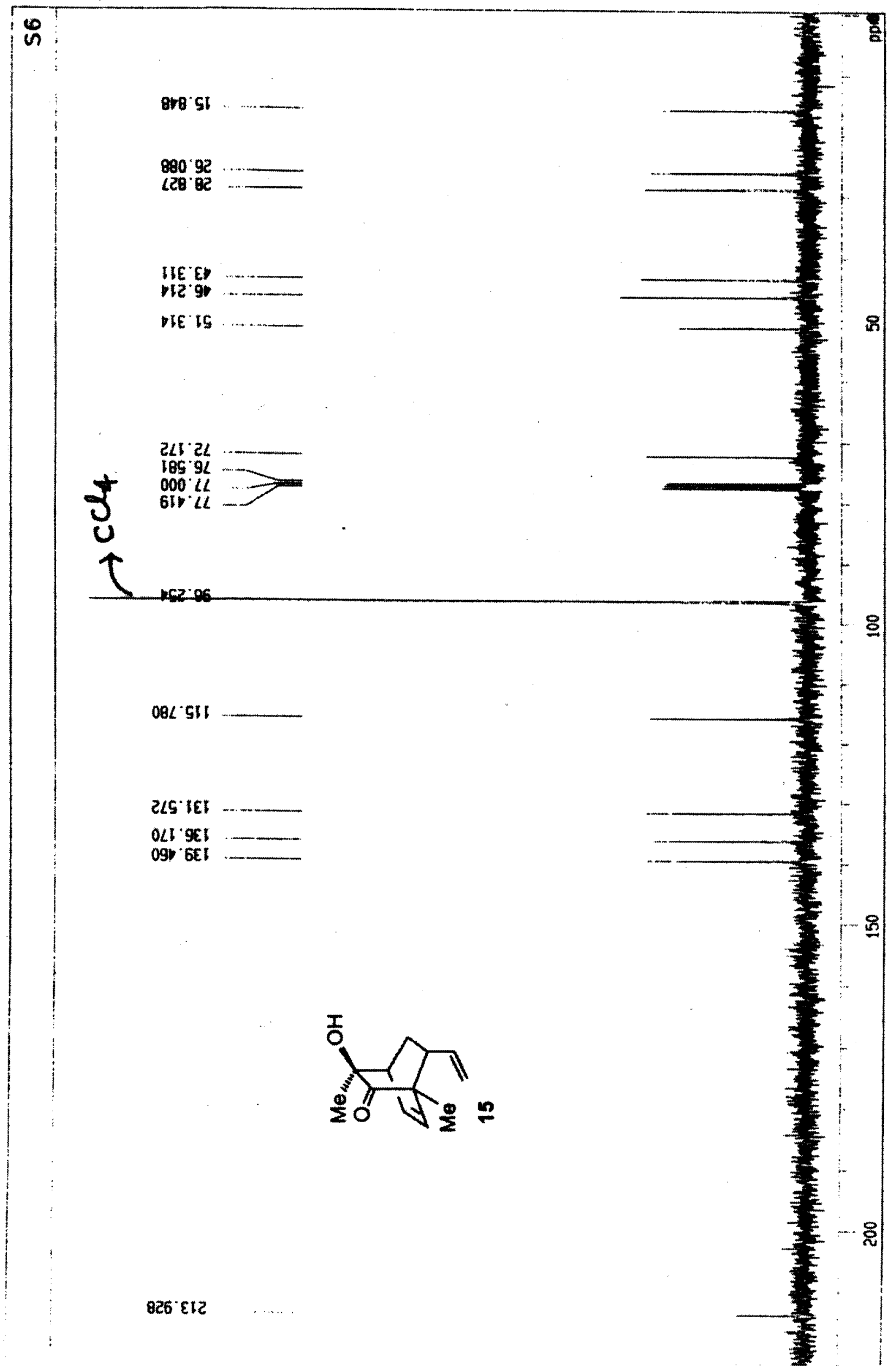




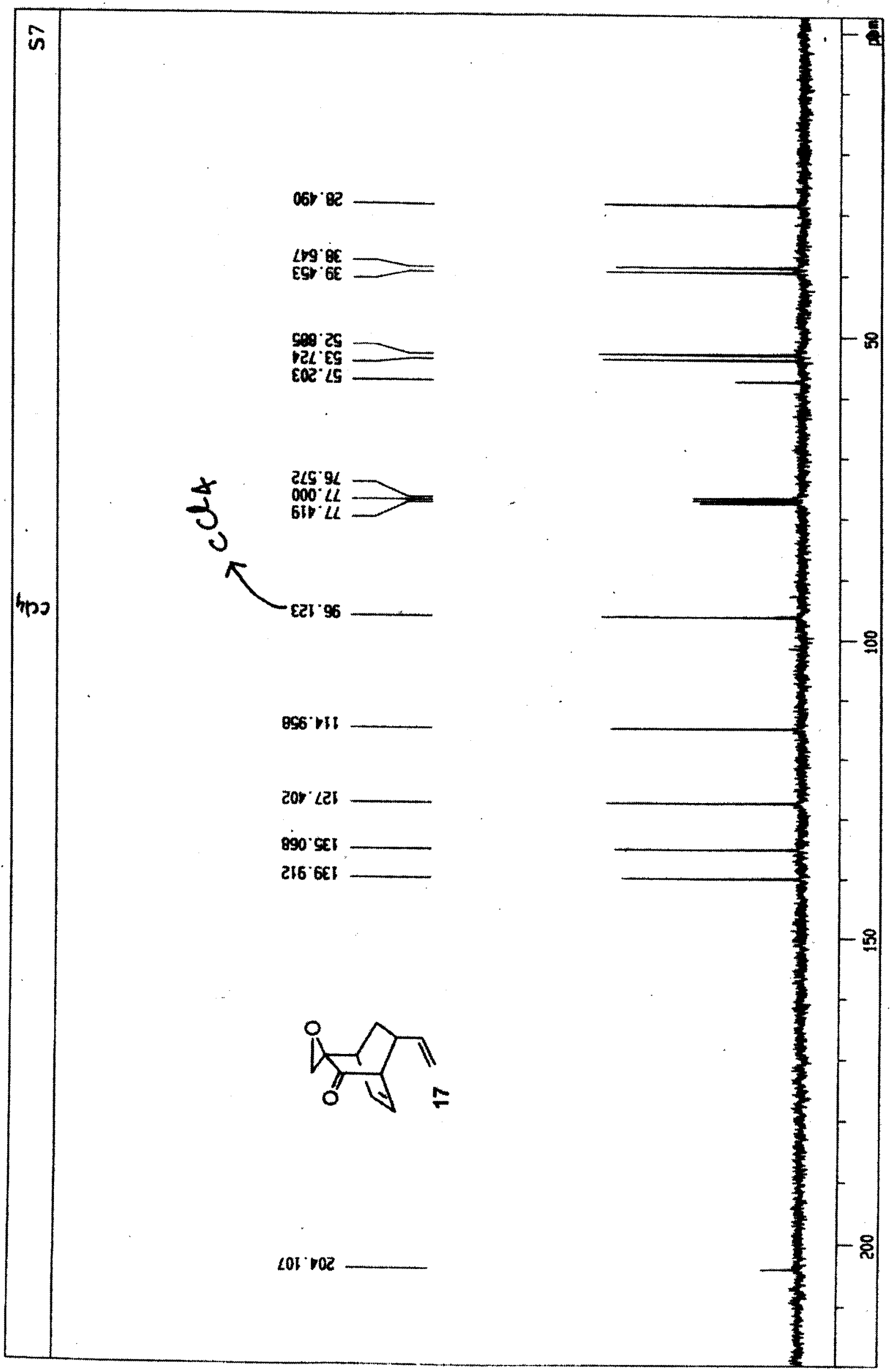




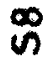

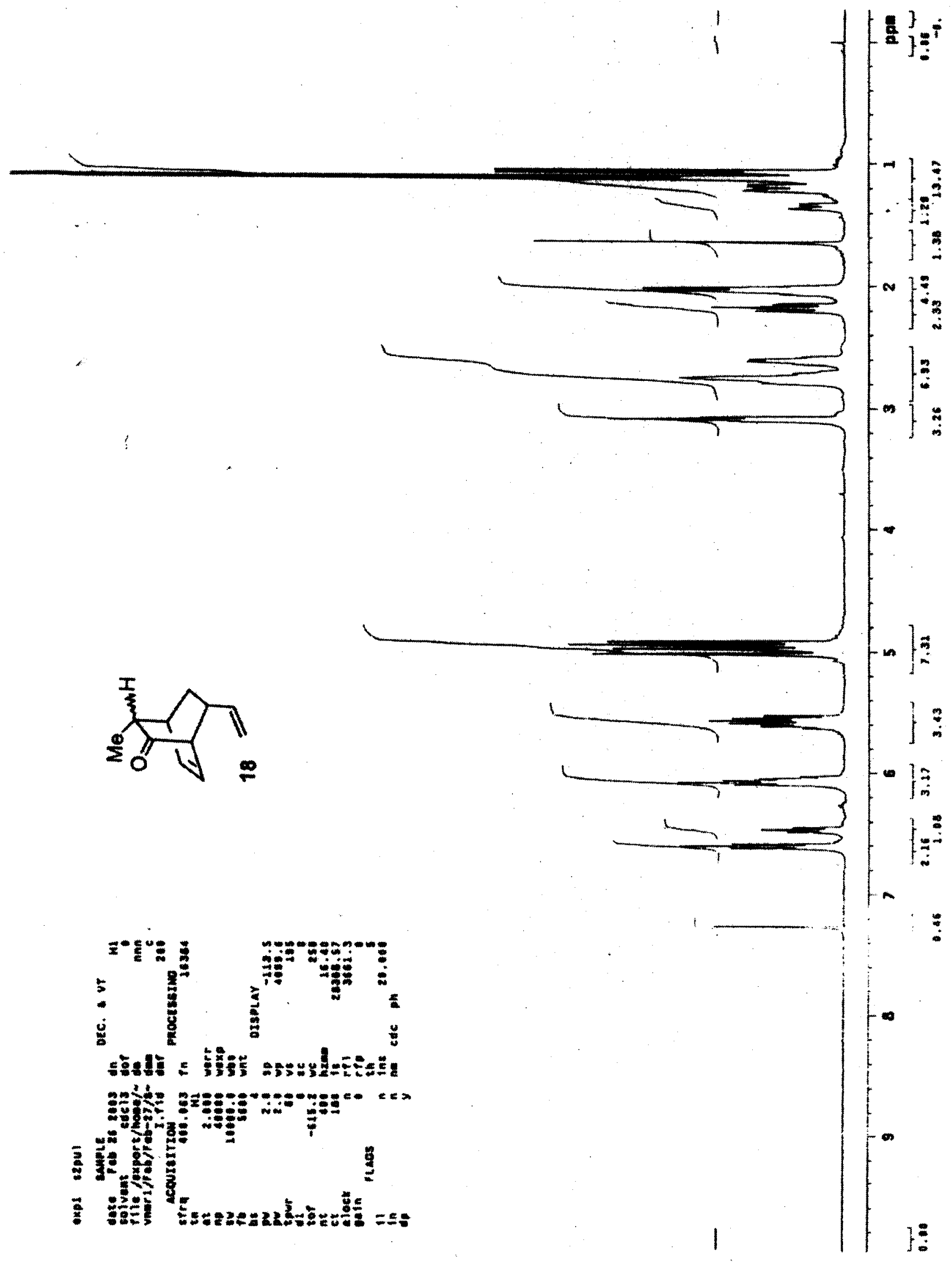


GRS"EE ..........

ISP. $\mathrm{SE}$

$195^{\circ} 0$

$969^{\circ} 5$

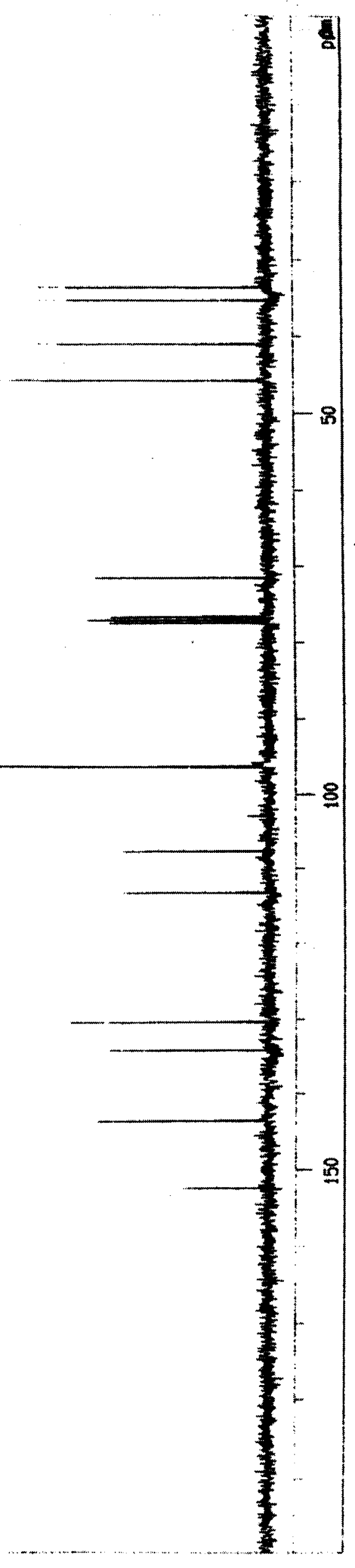

SSE OEI

GZ2' $\mathrm{El}$

sts.eb

$162 \cdot 291$

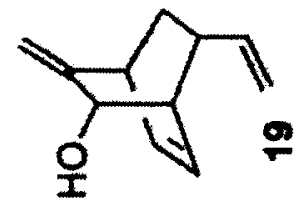




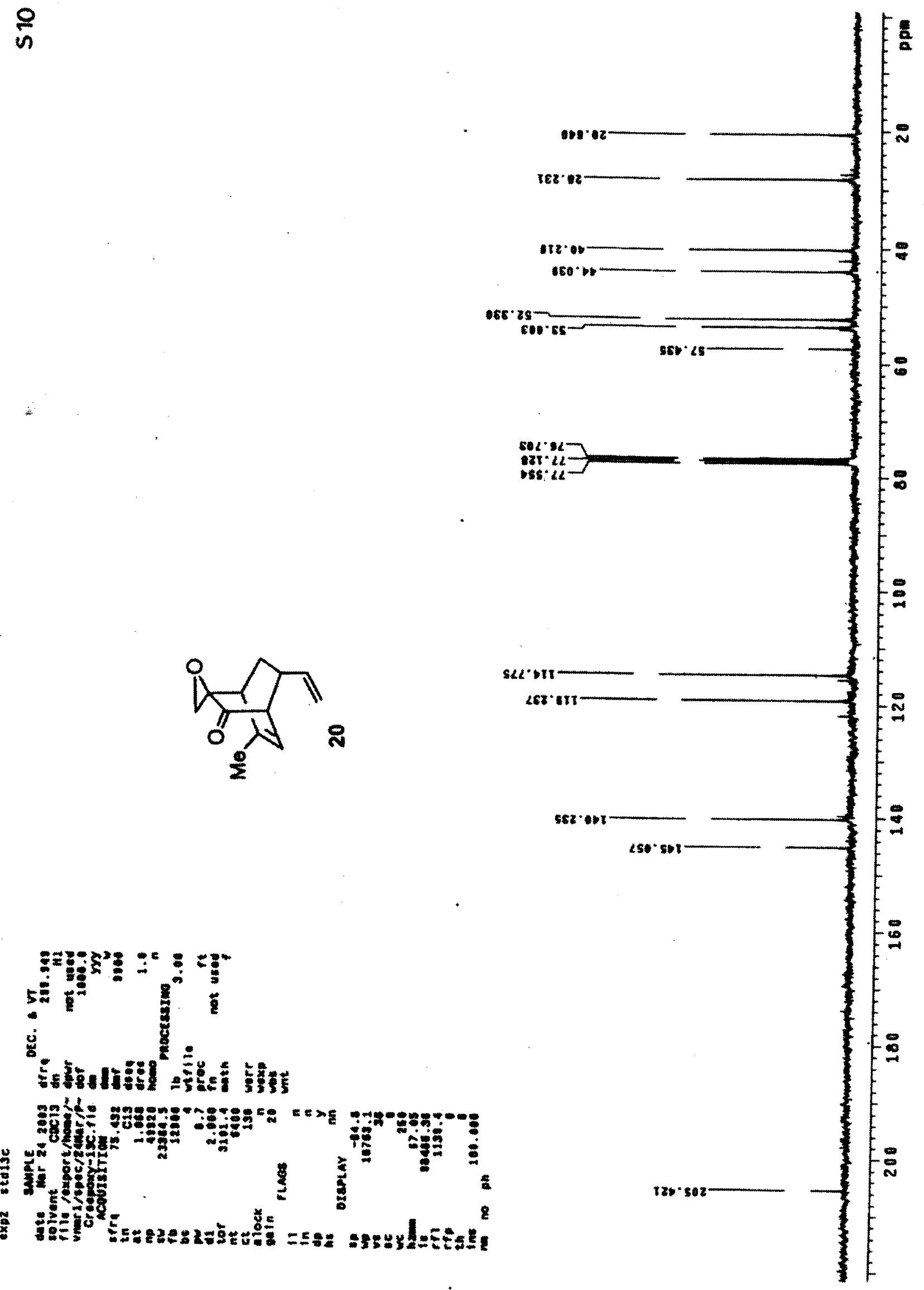


$=$

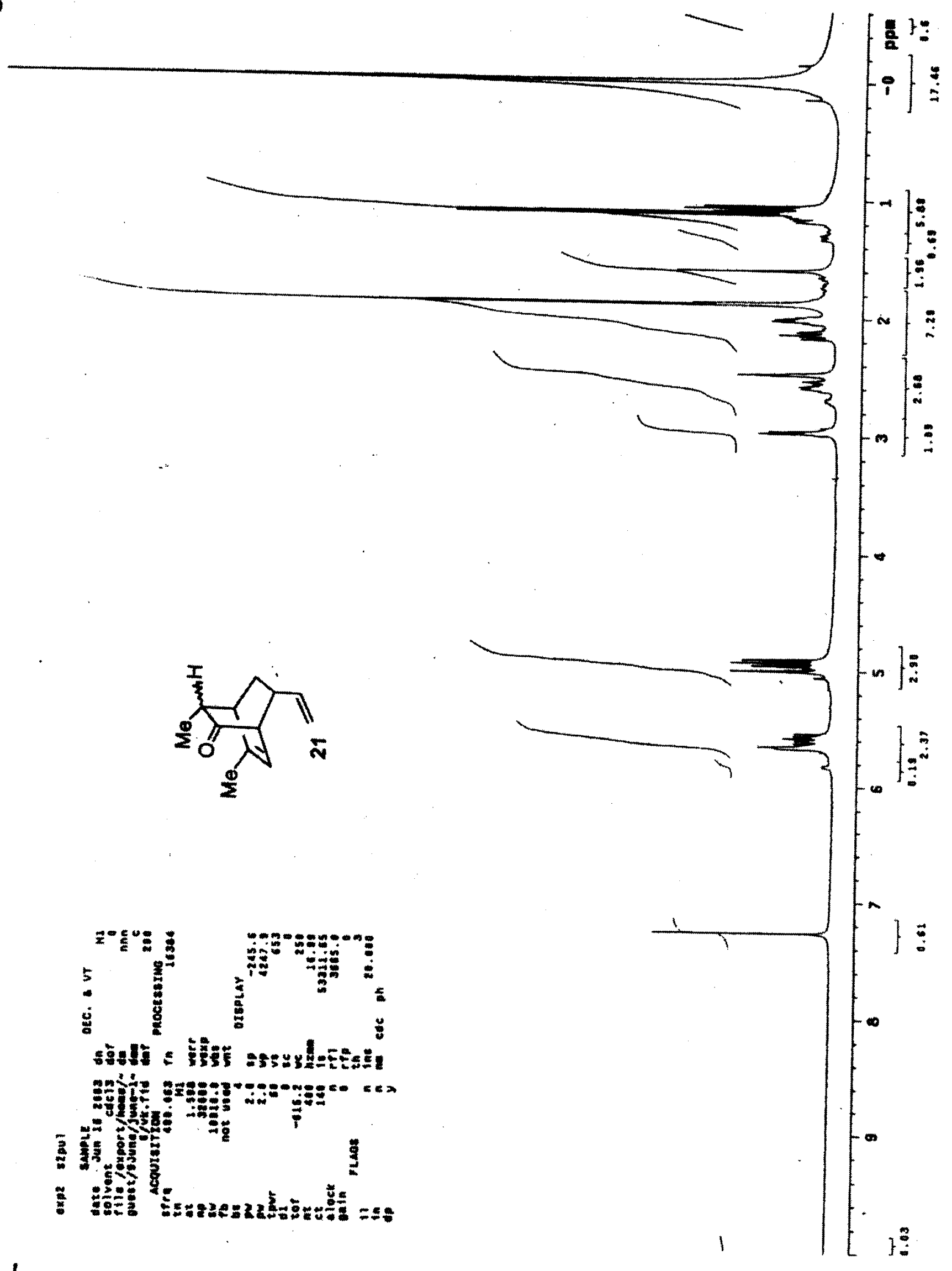




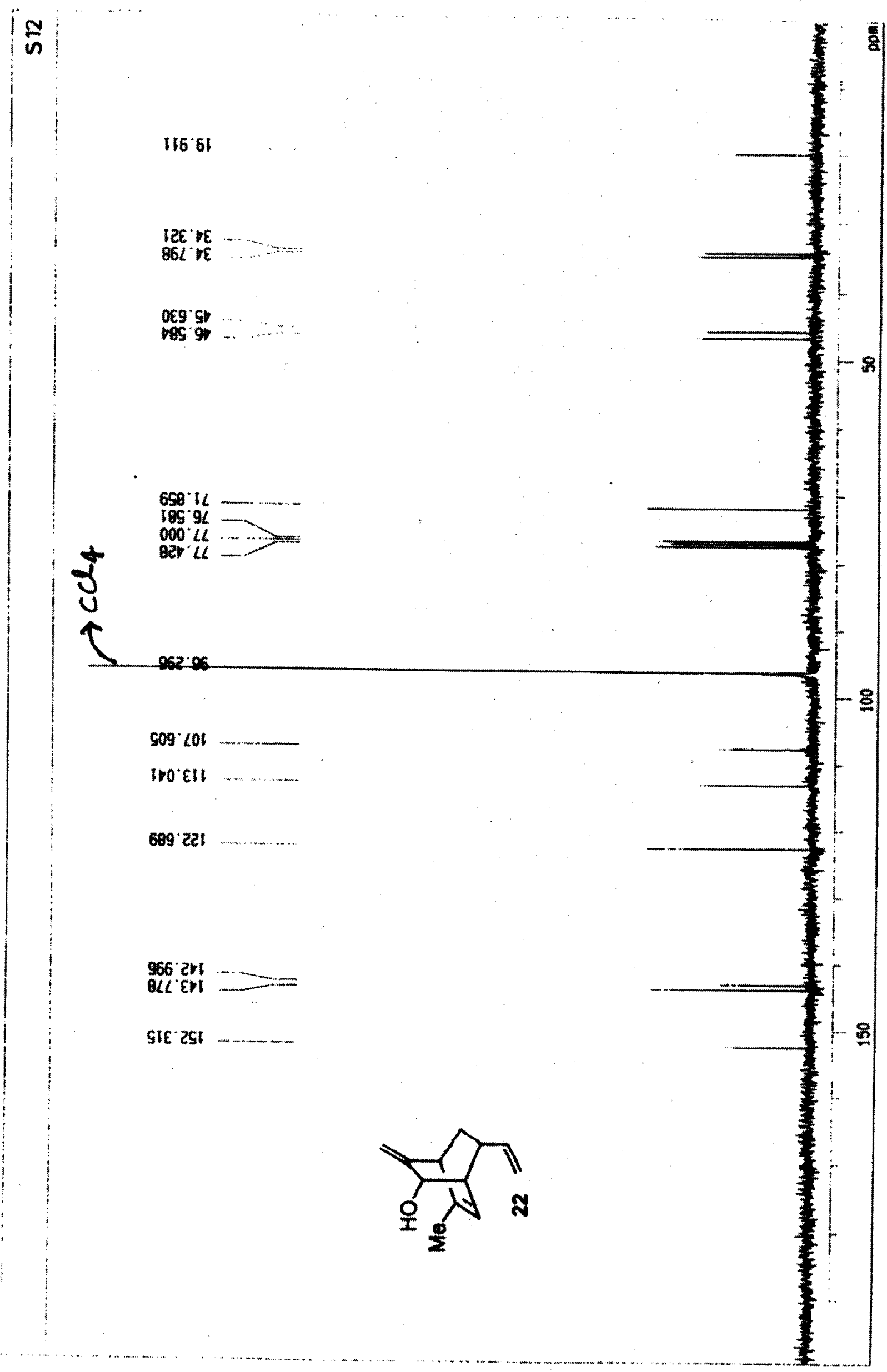




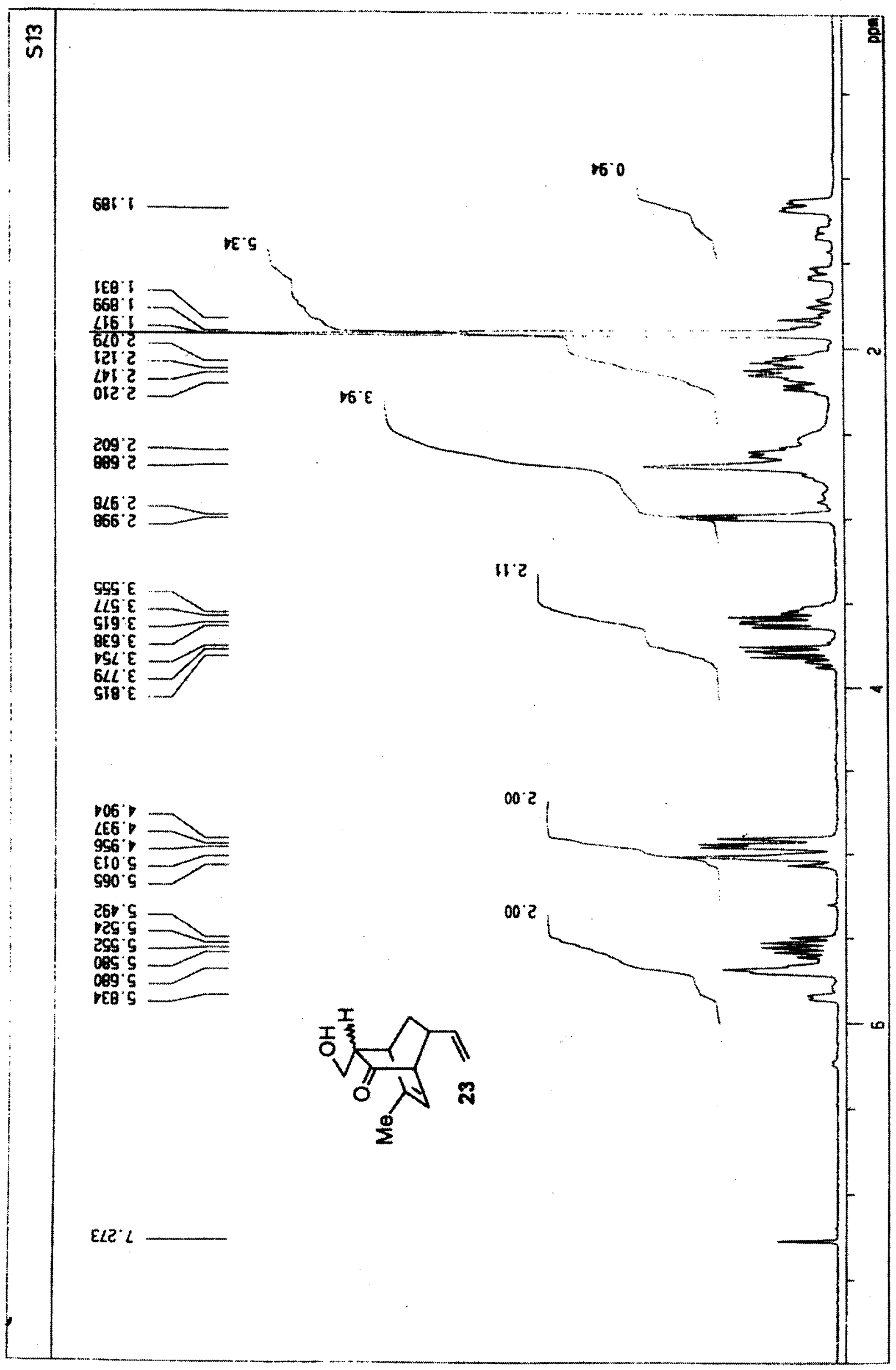




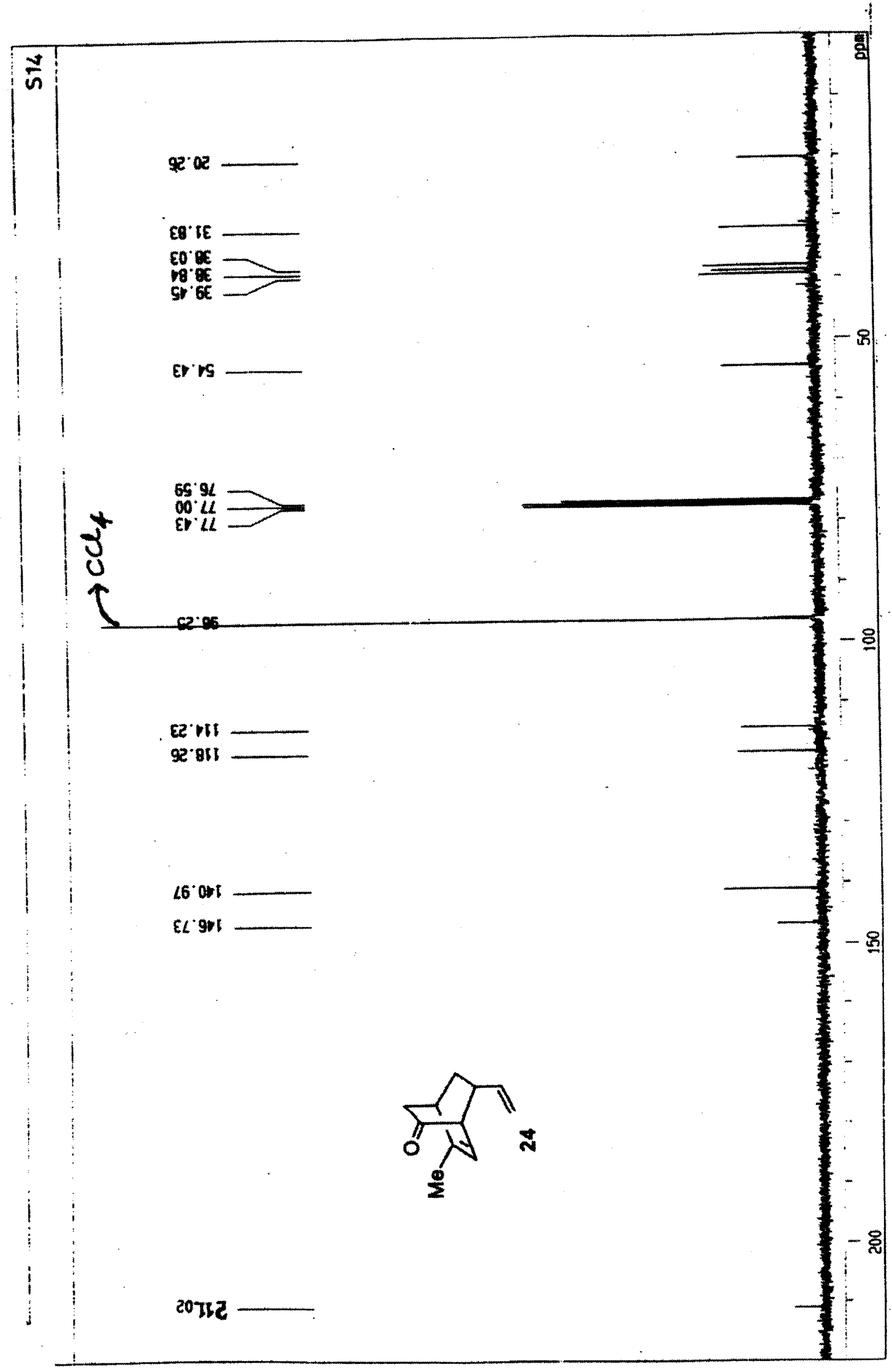


$\frac{n}{n}$
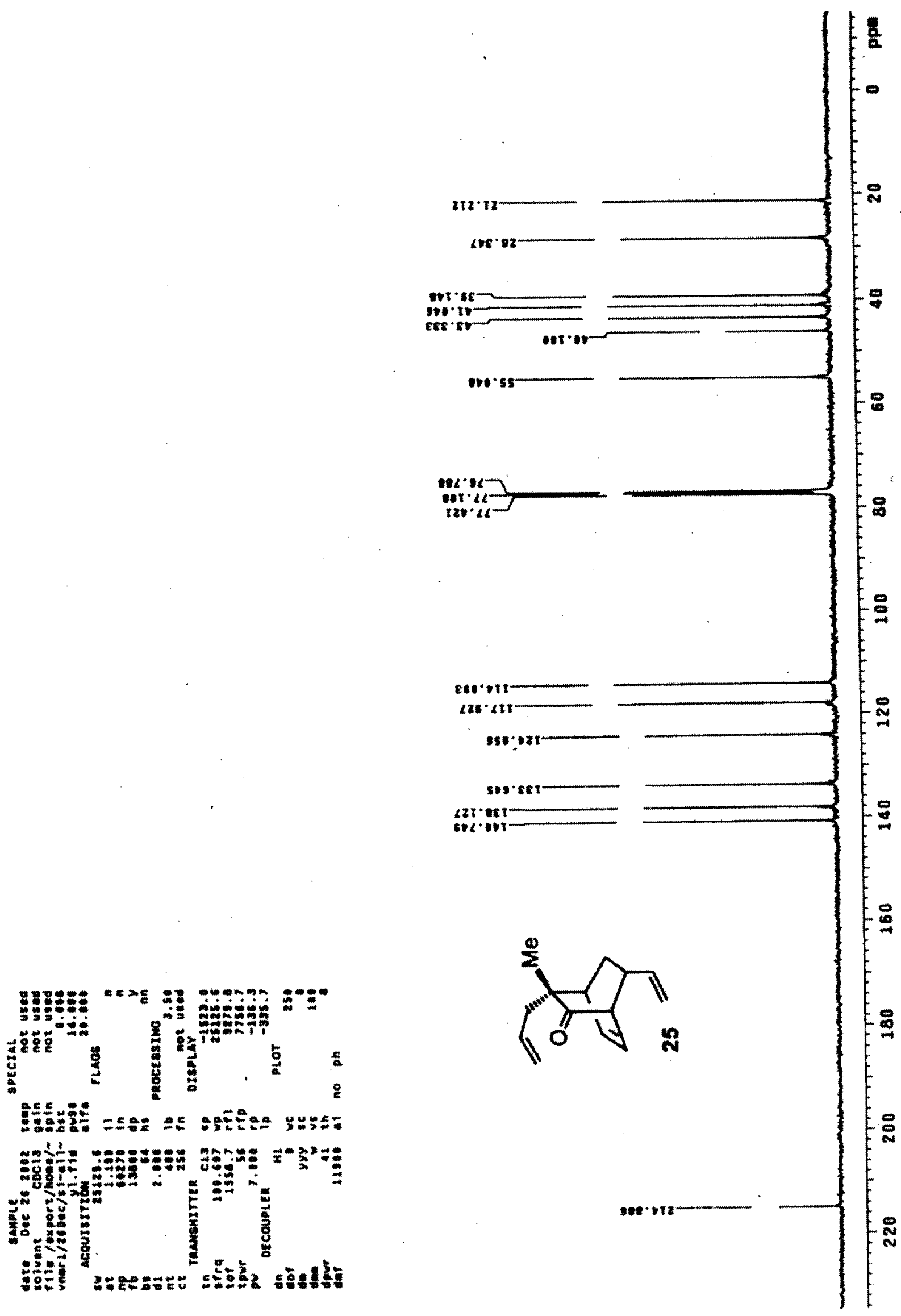
$\frac{n}{n}$
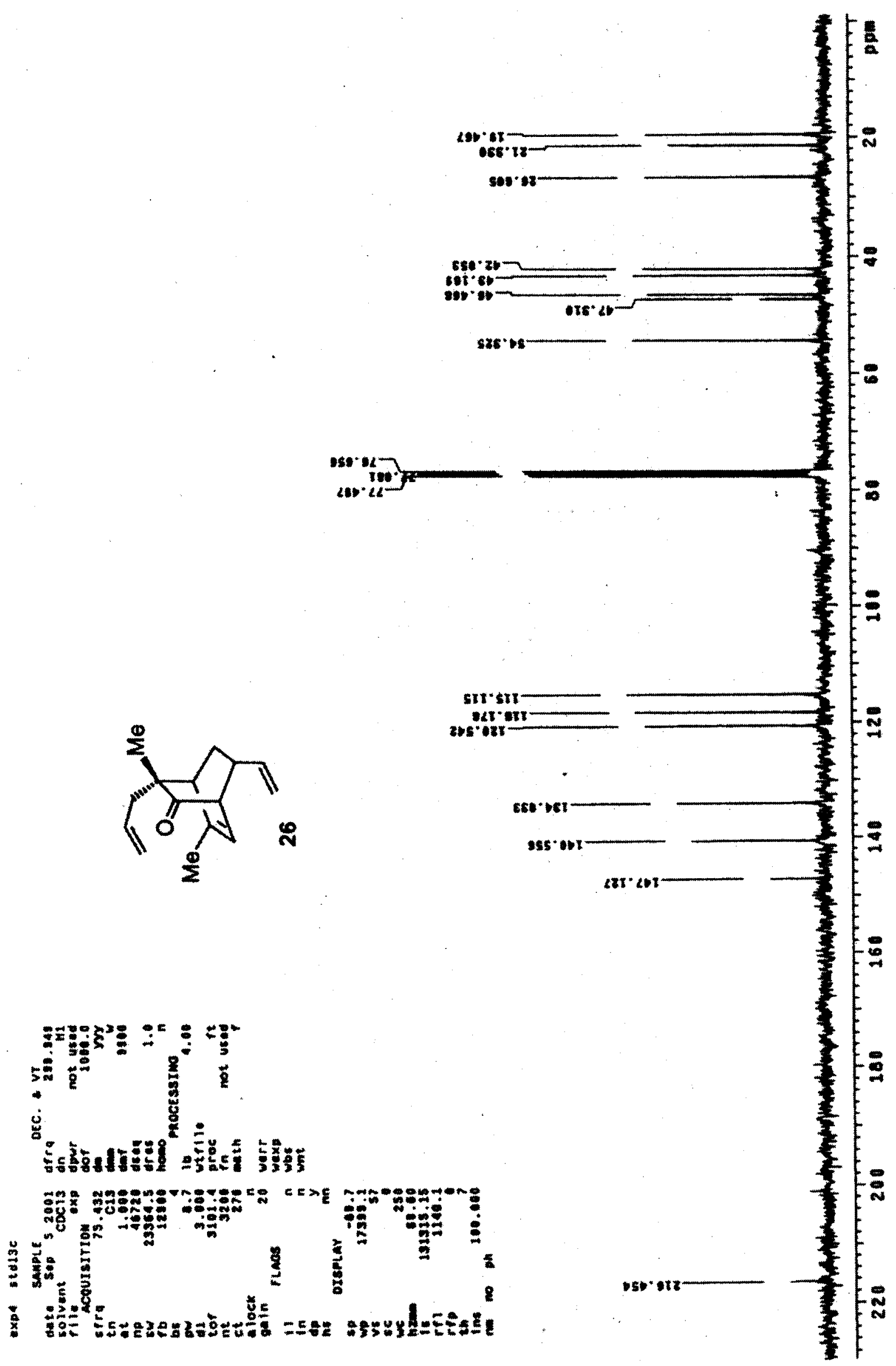


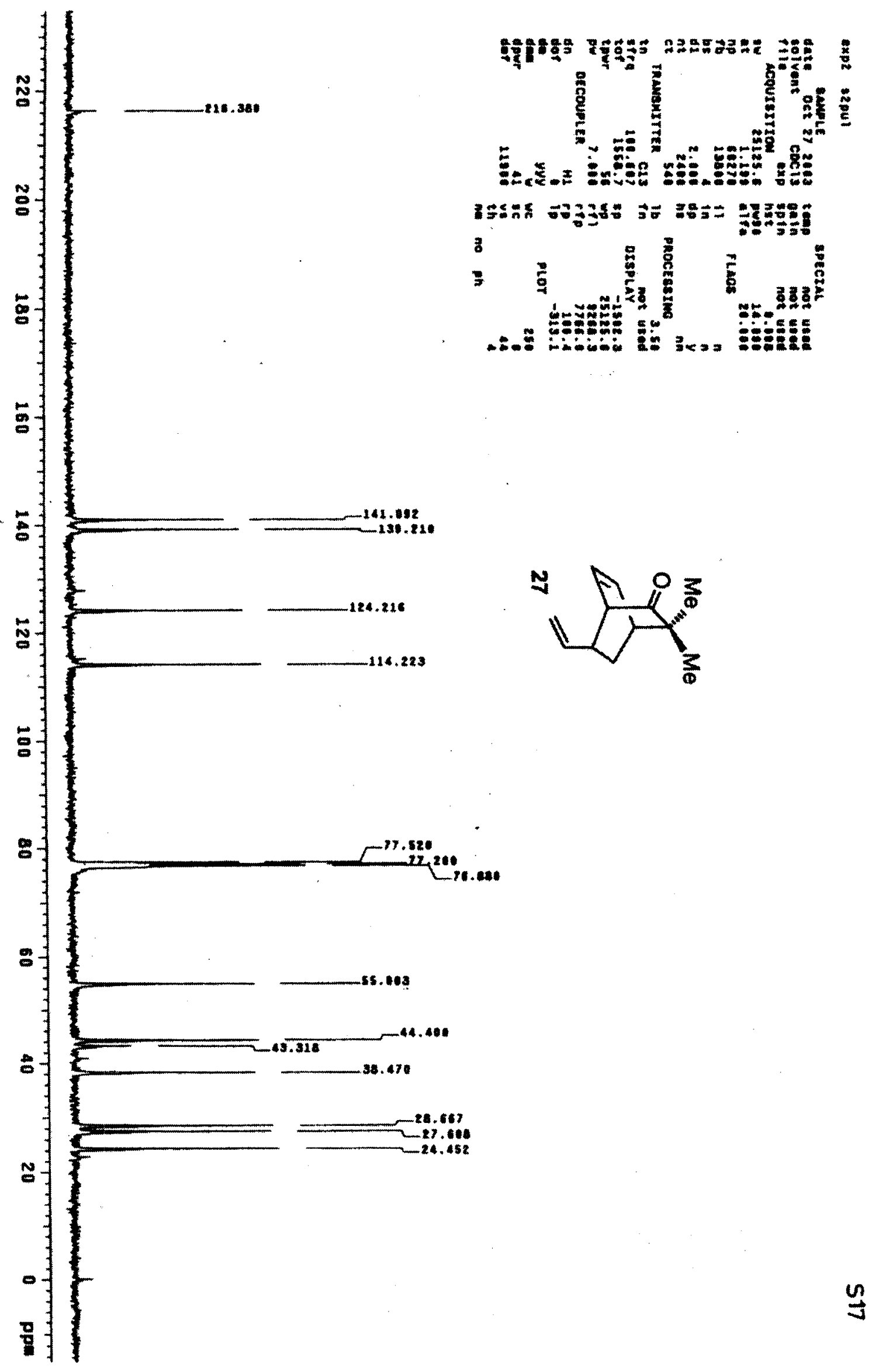




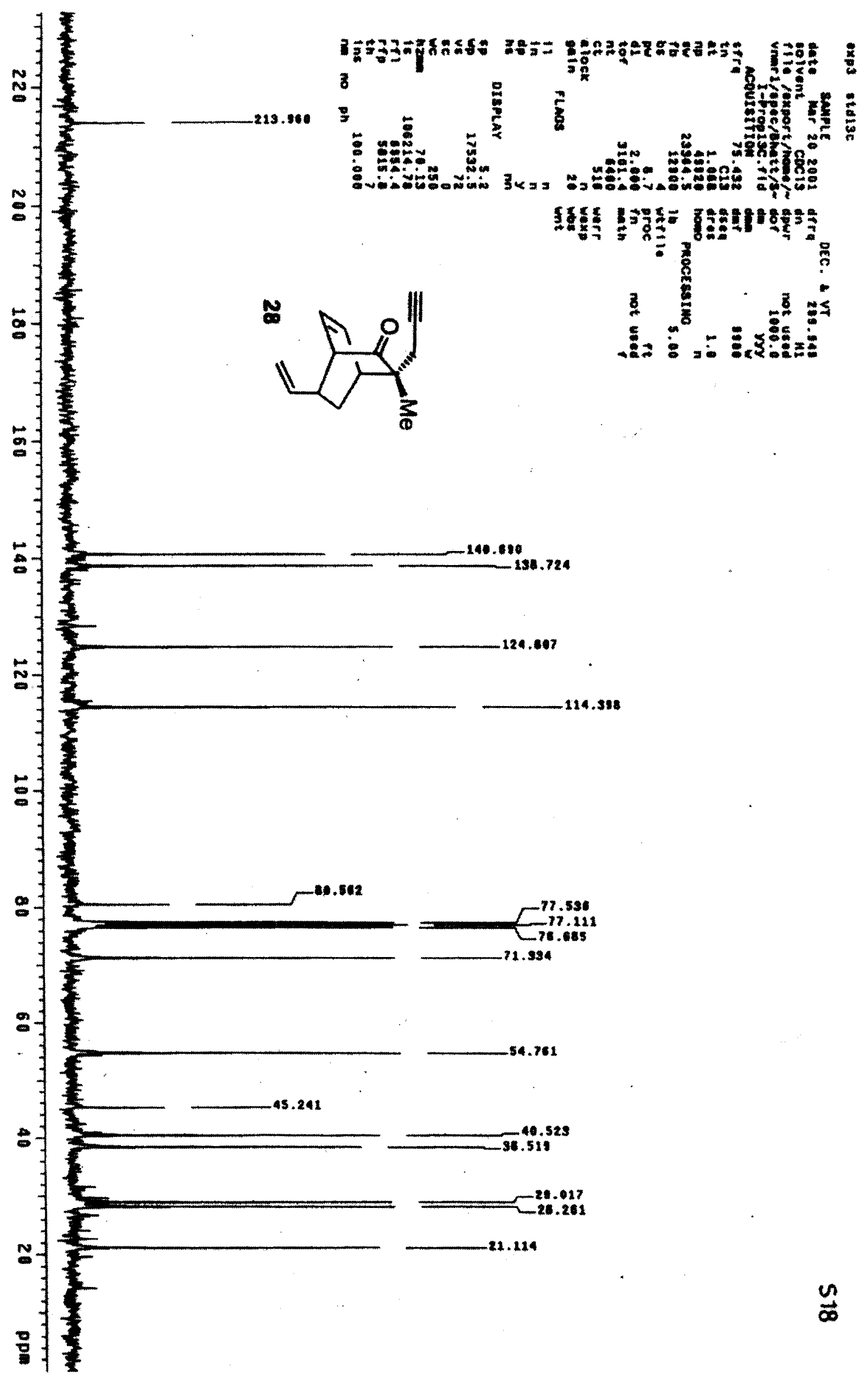




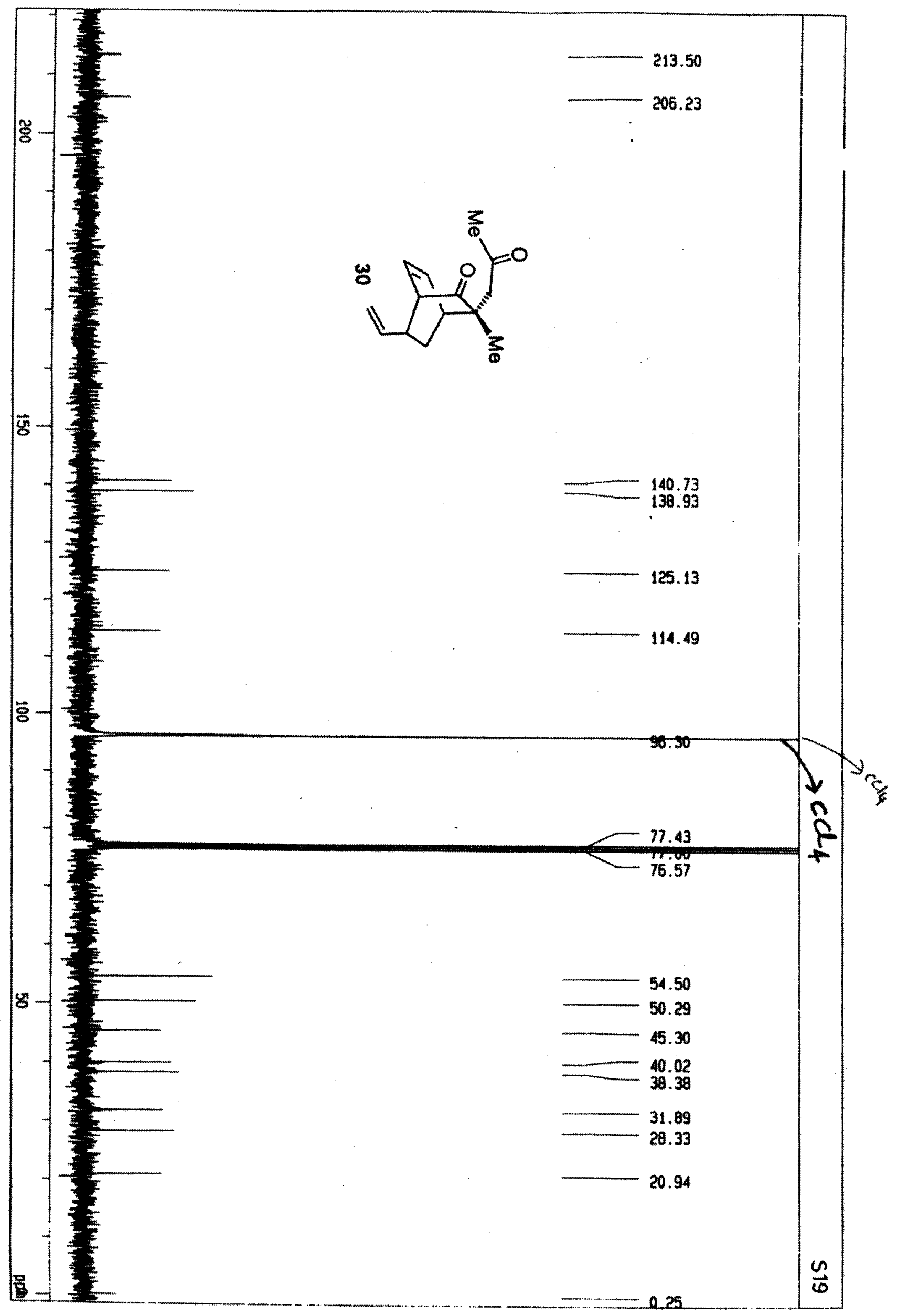




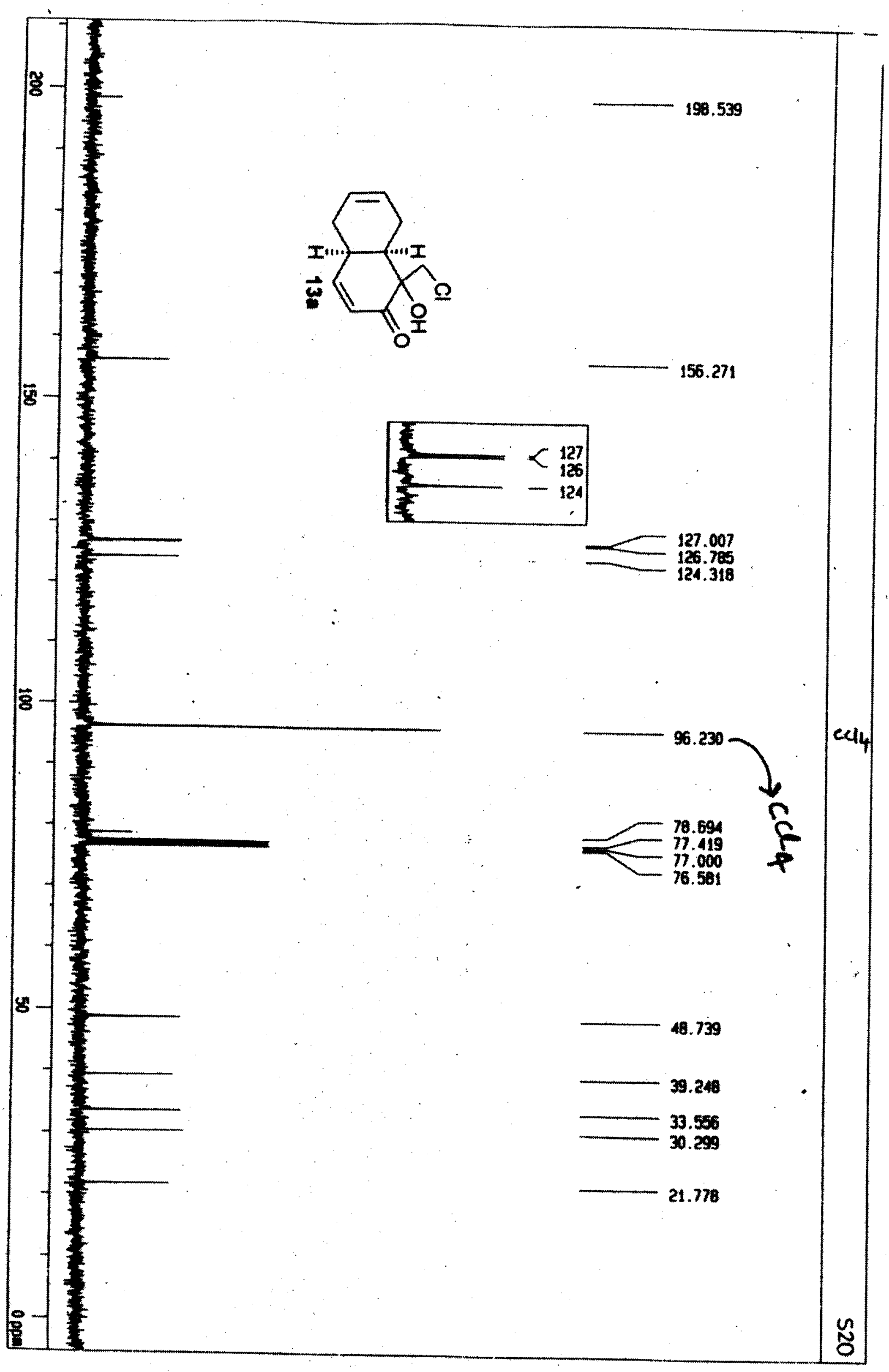




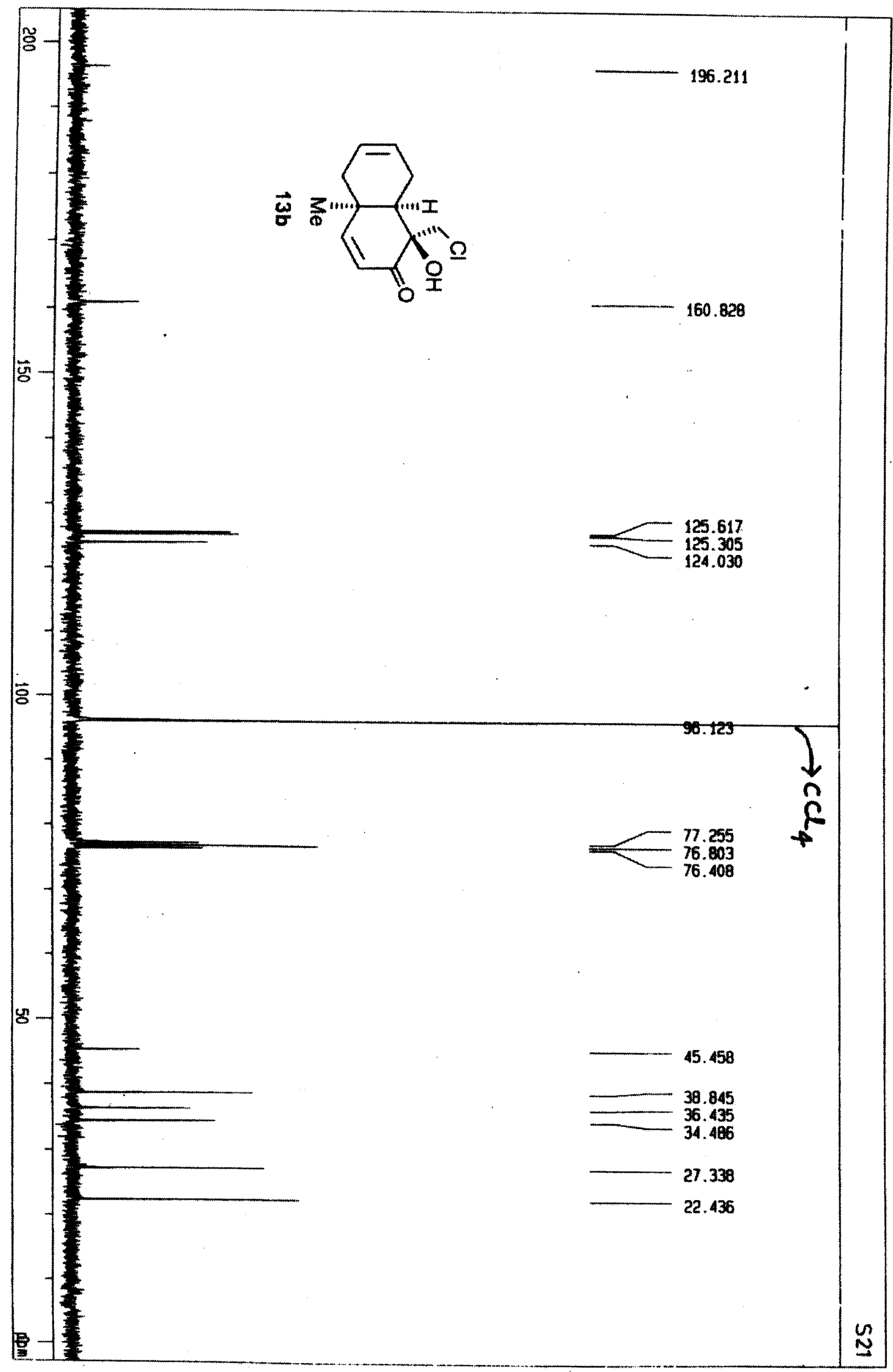




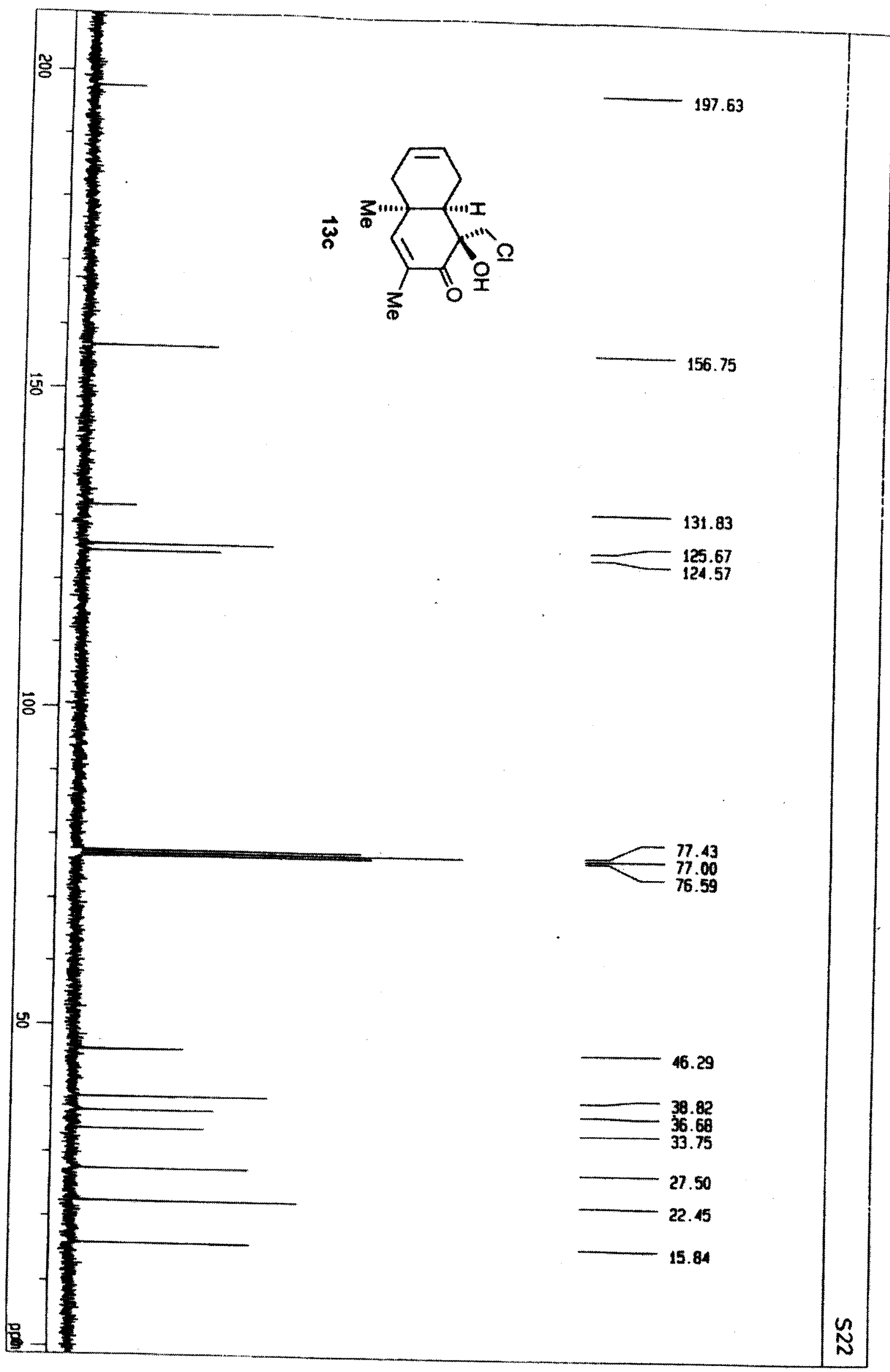




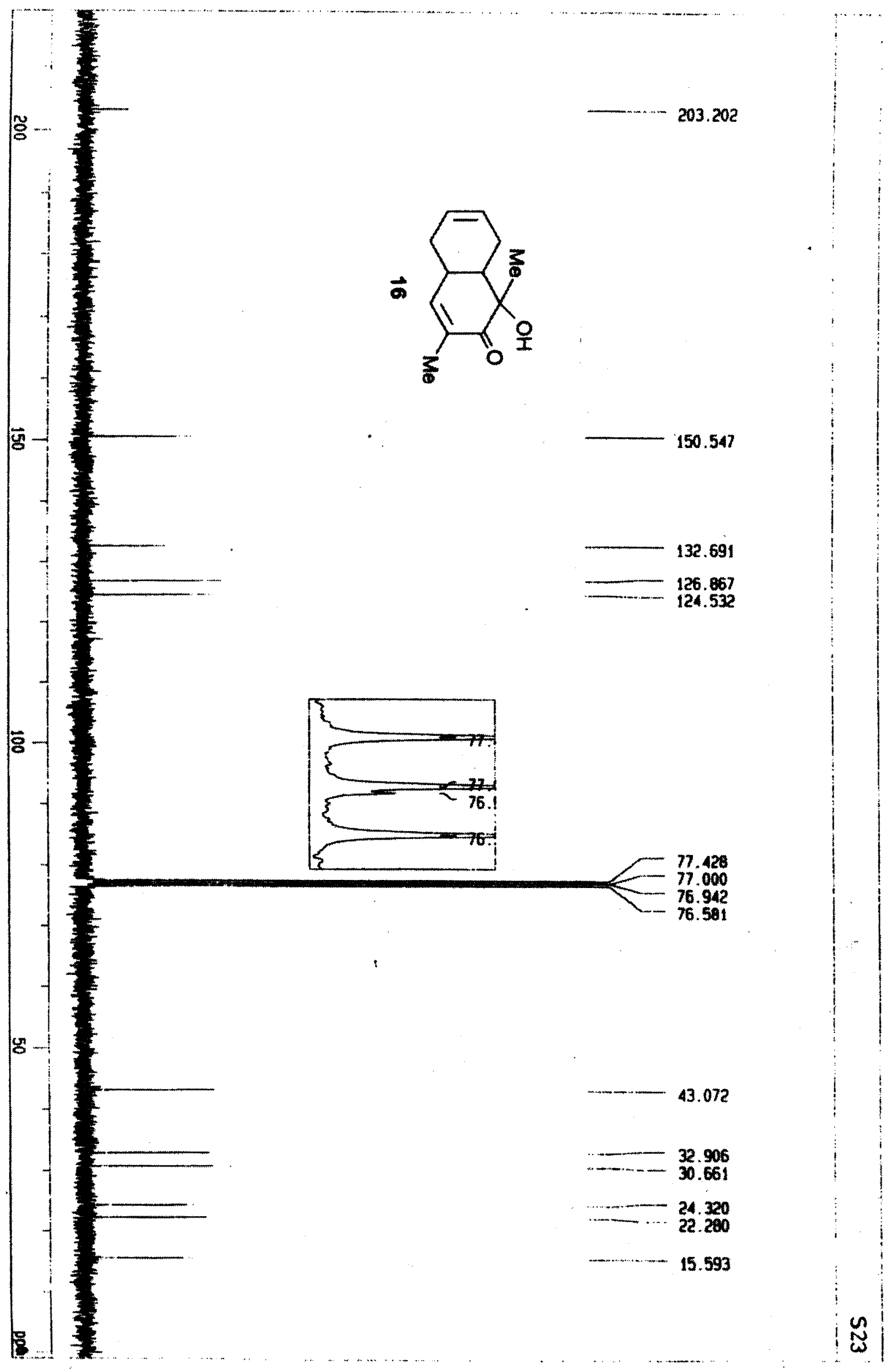




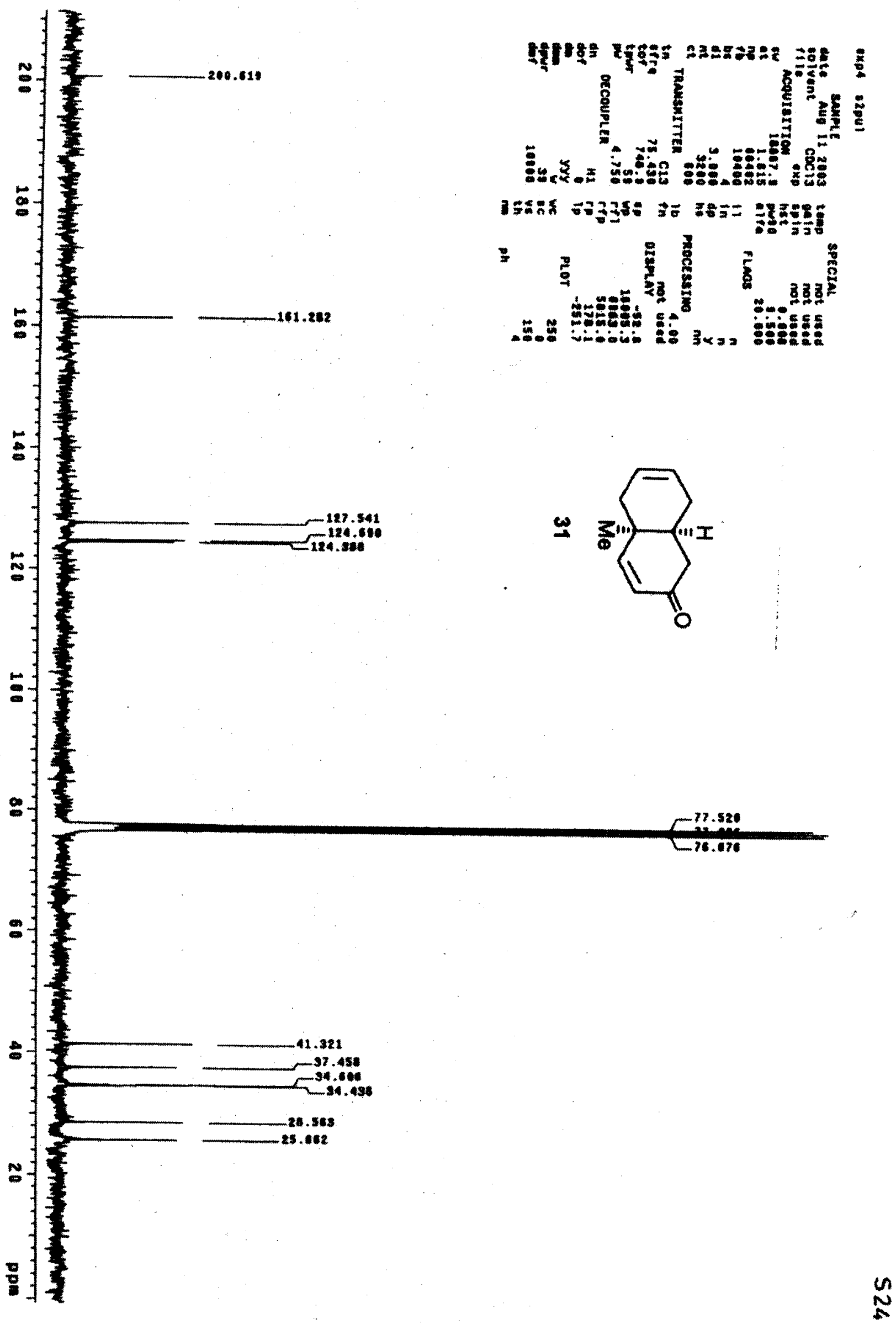




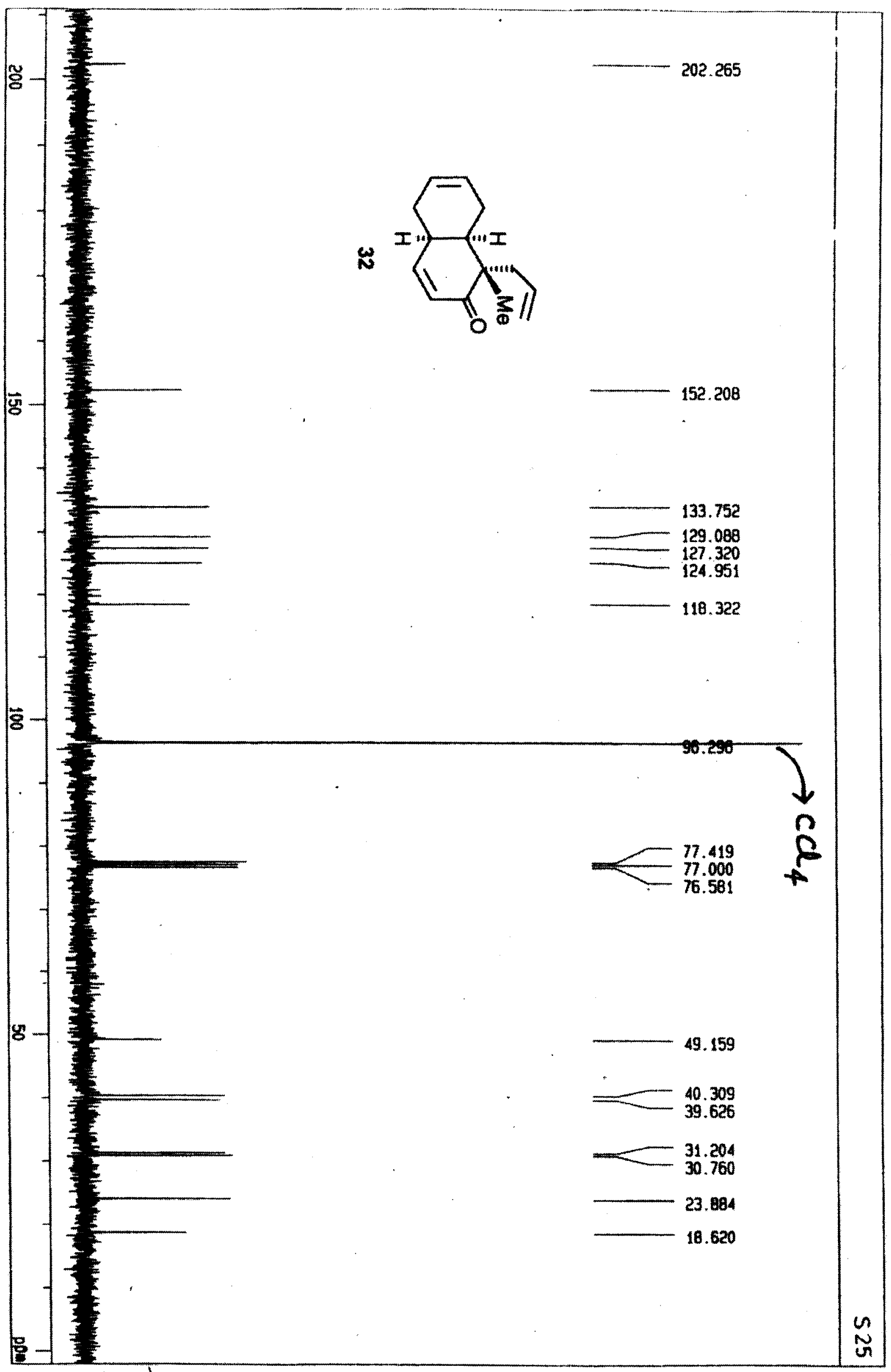



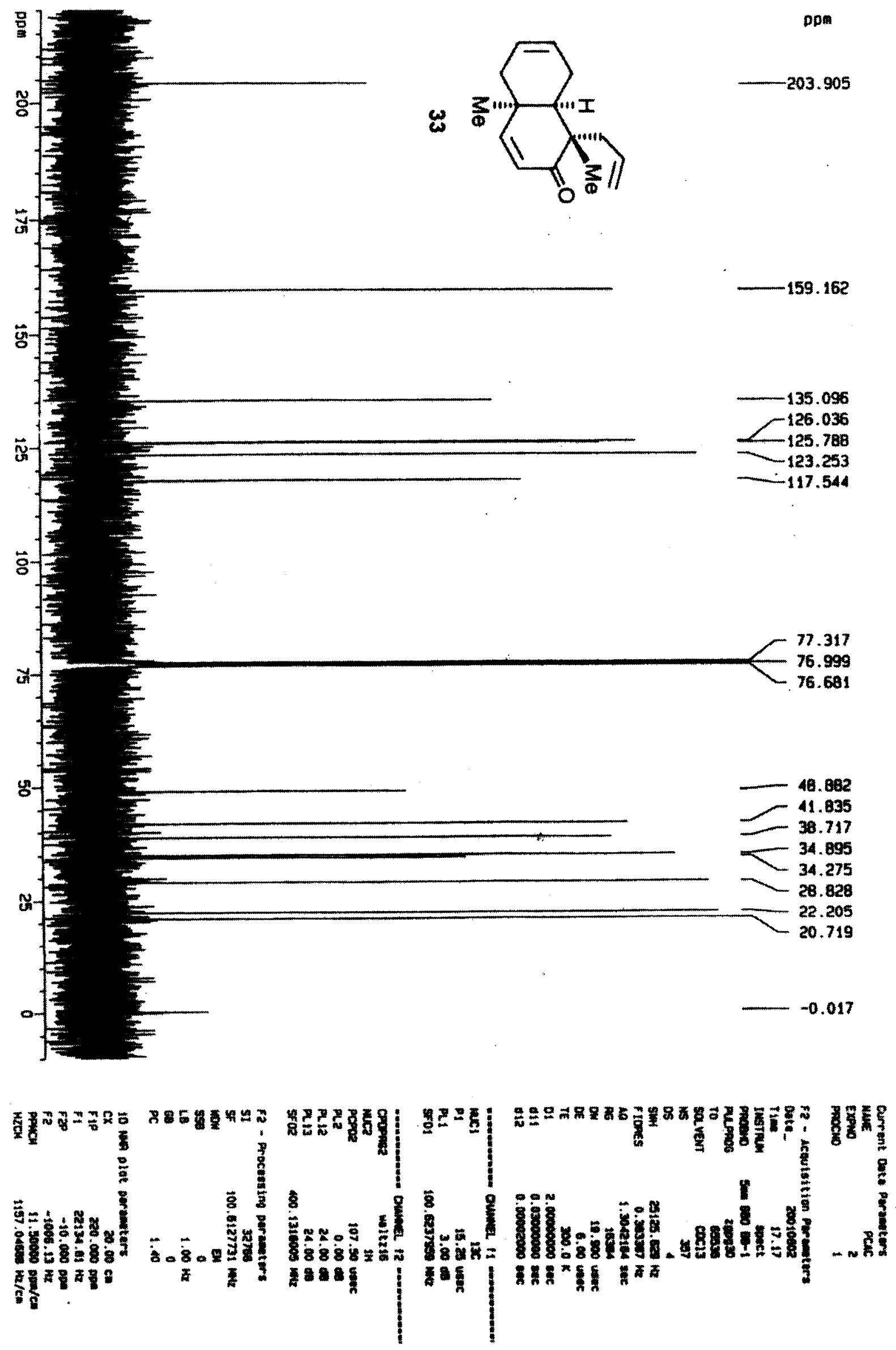

N 


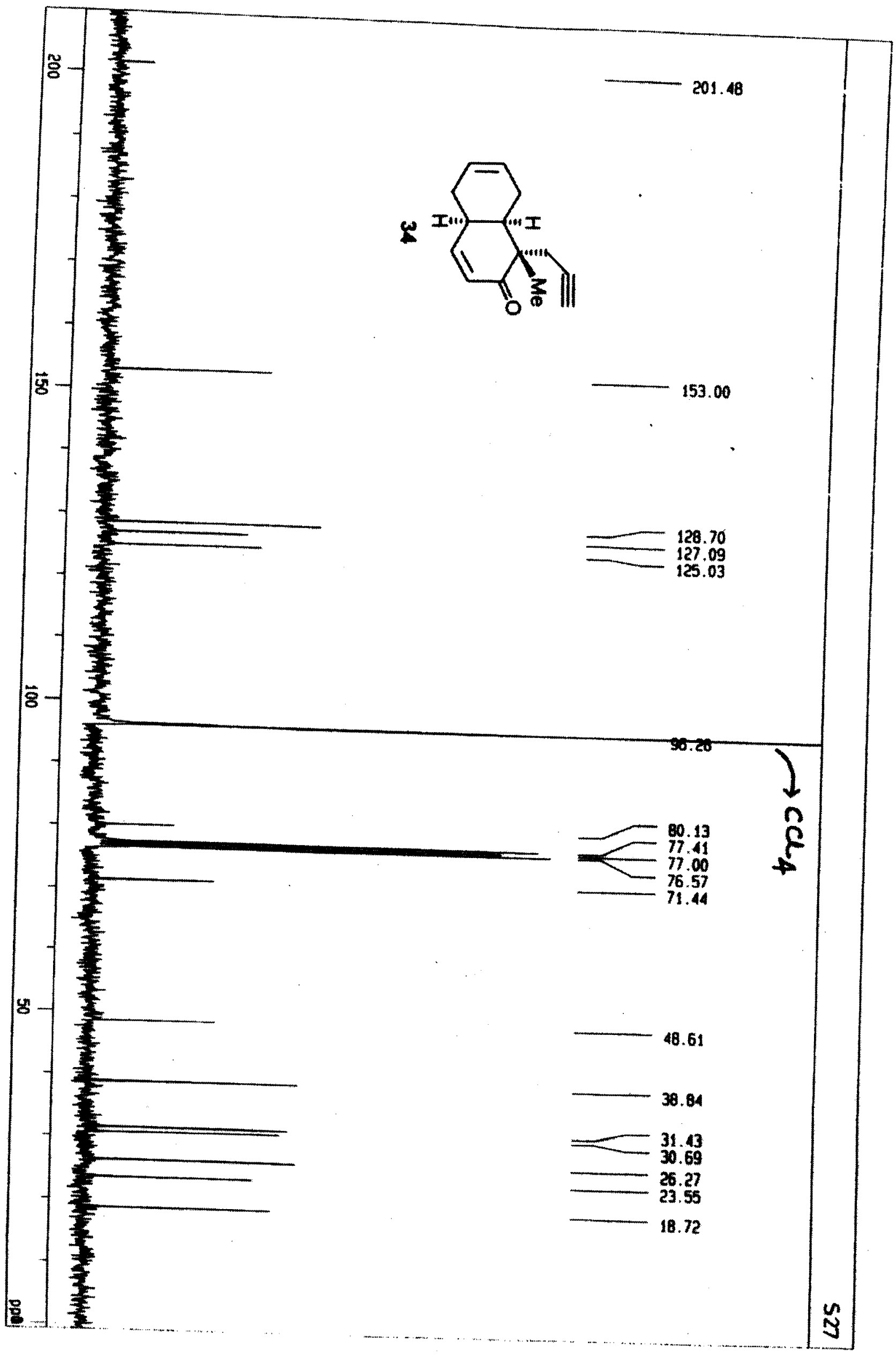




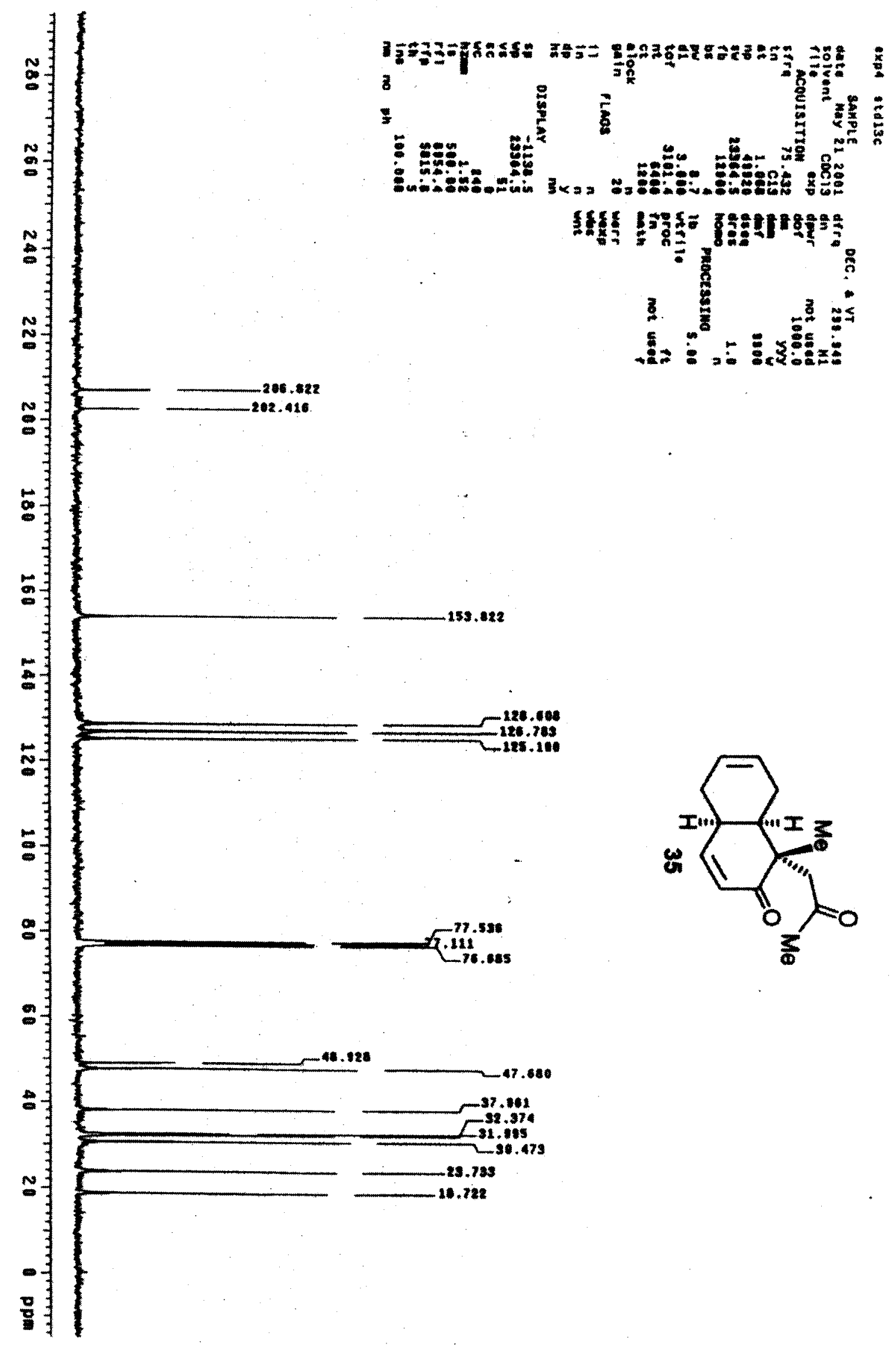




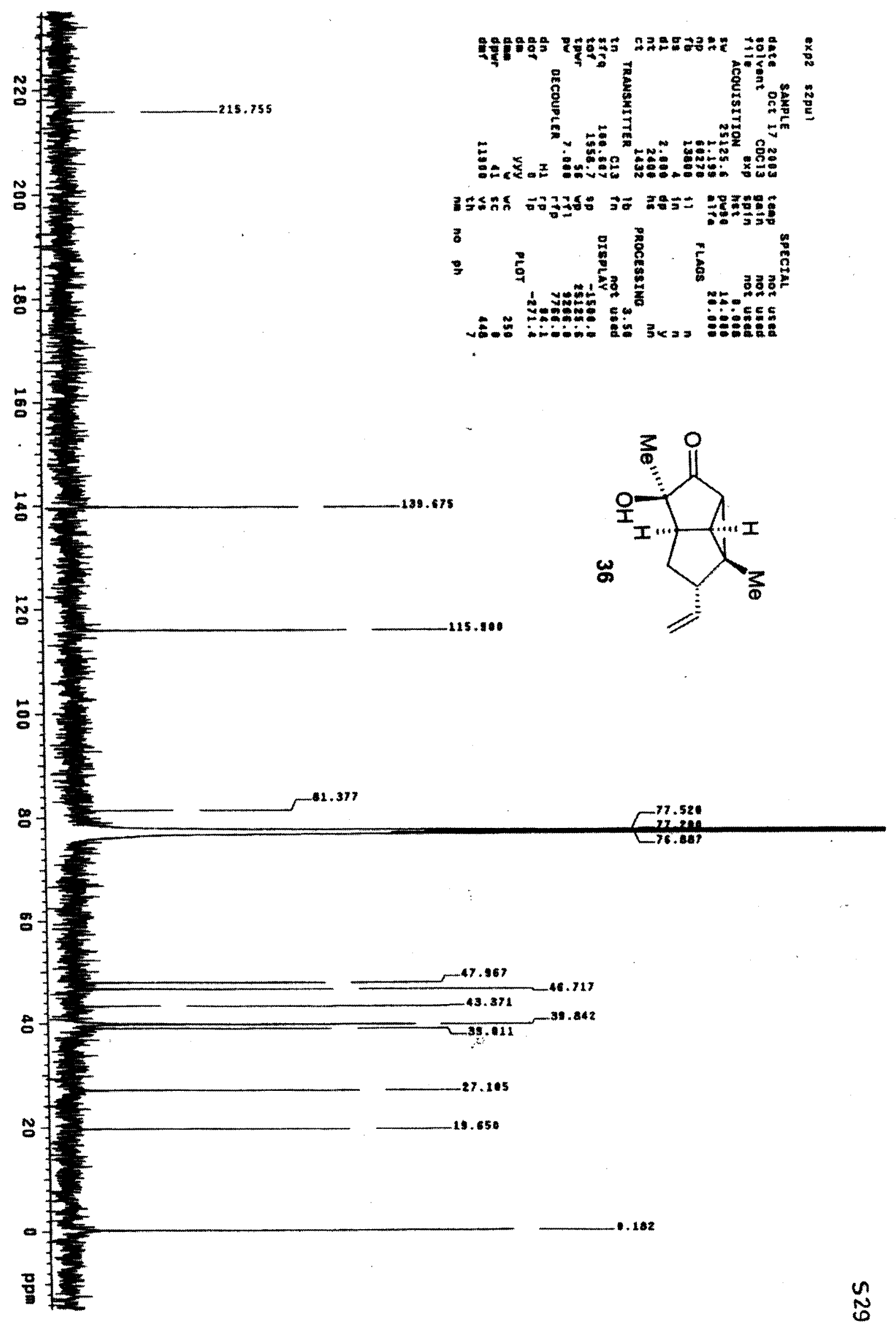




$$
\mid
$$




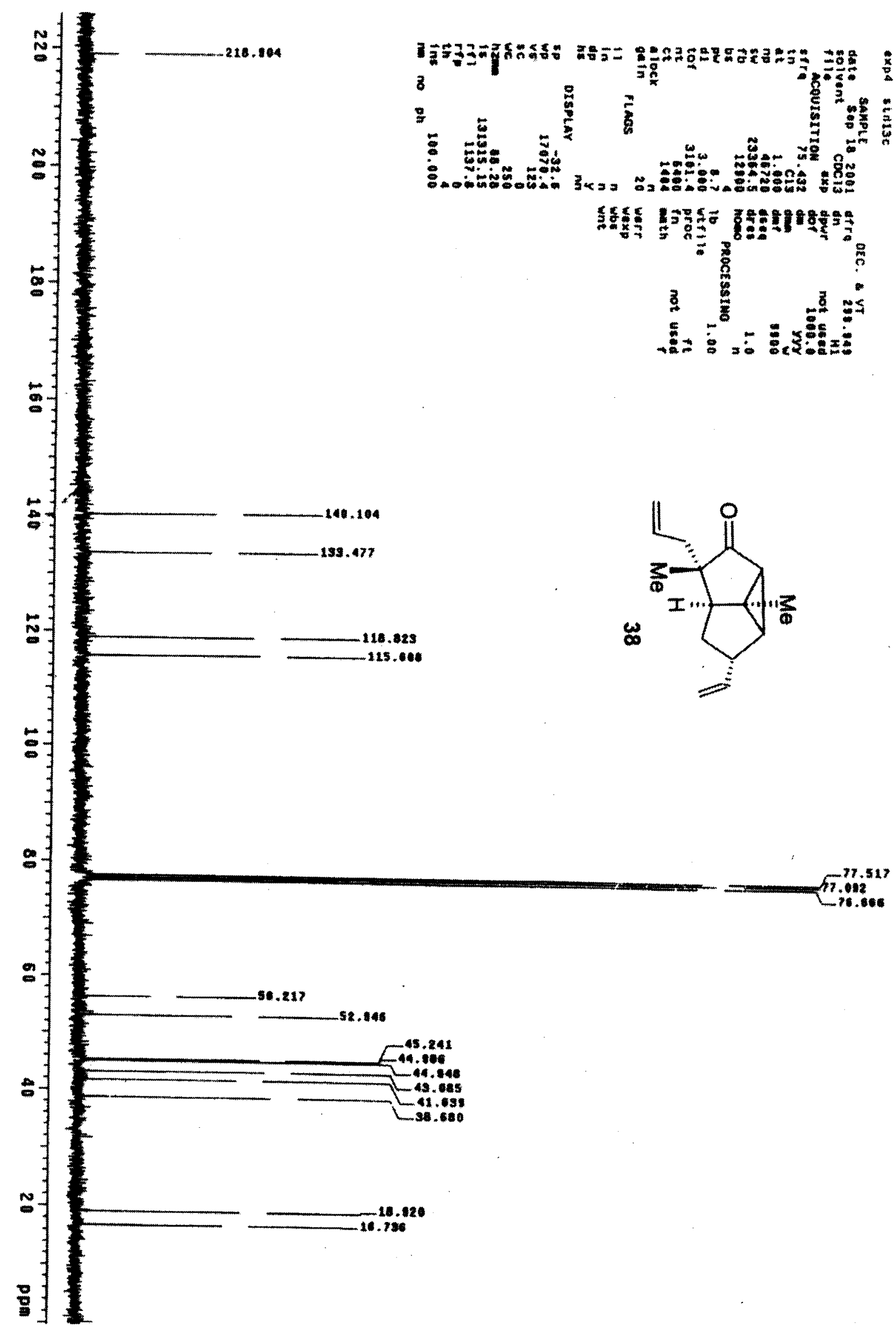




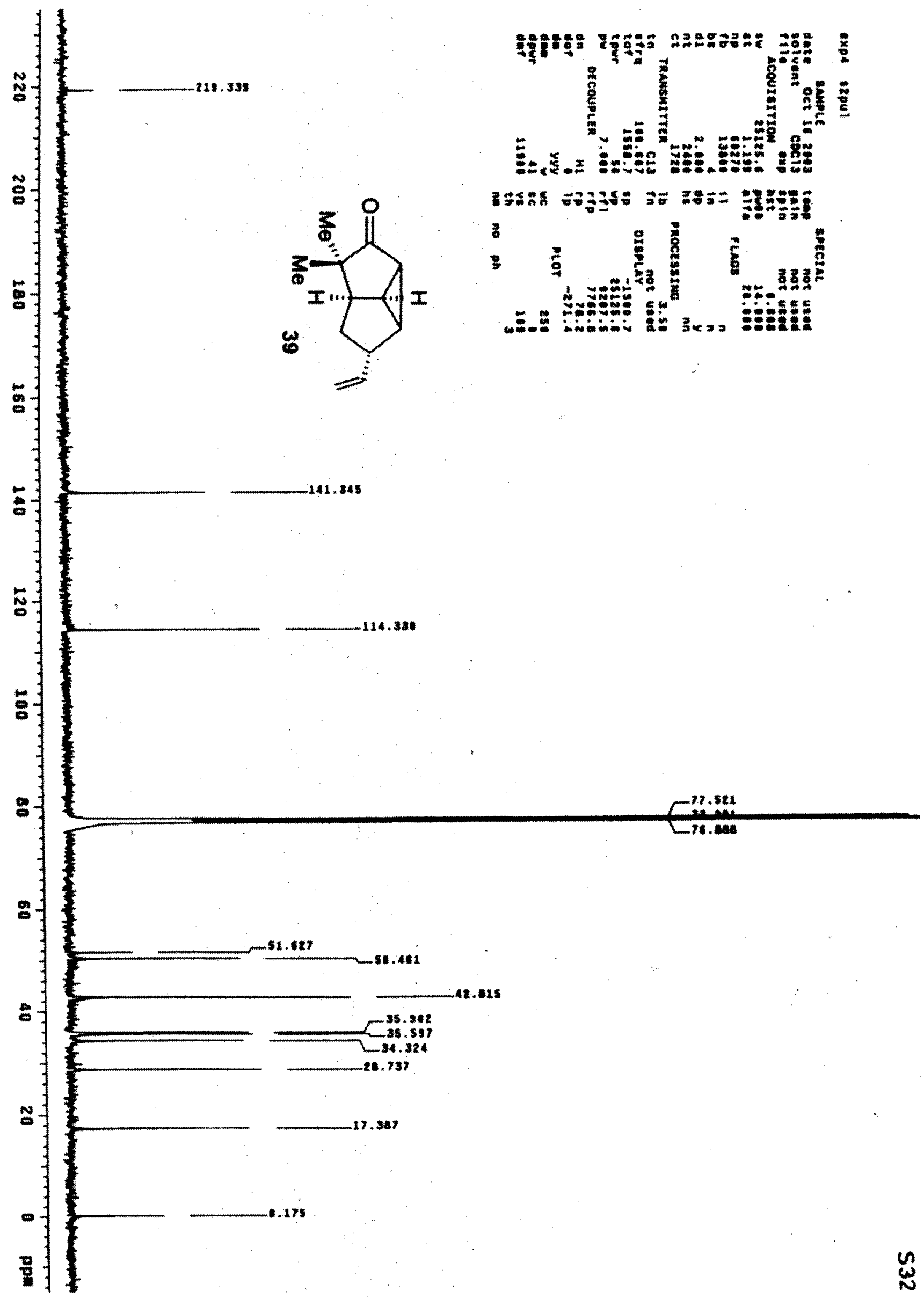




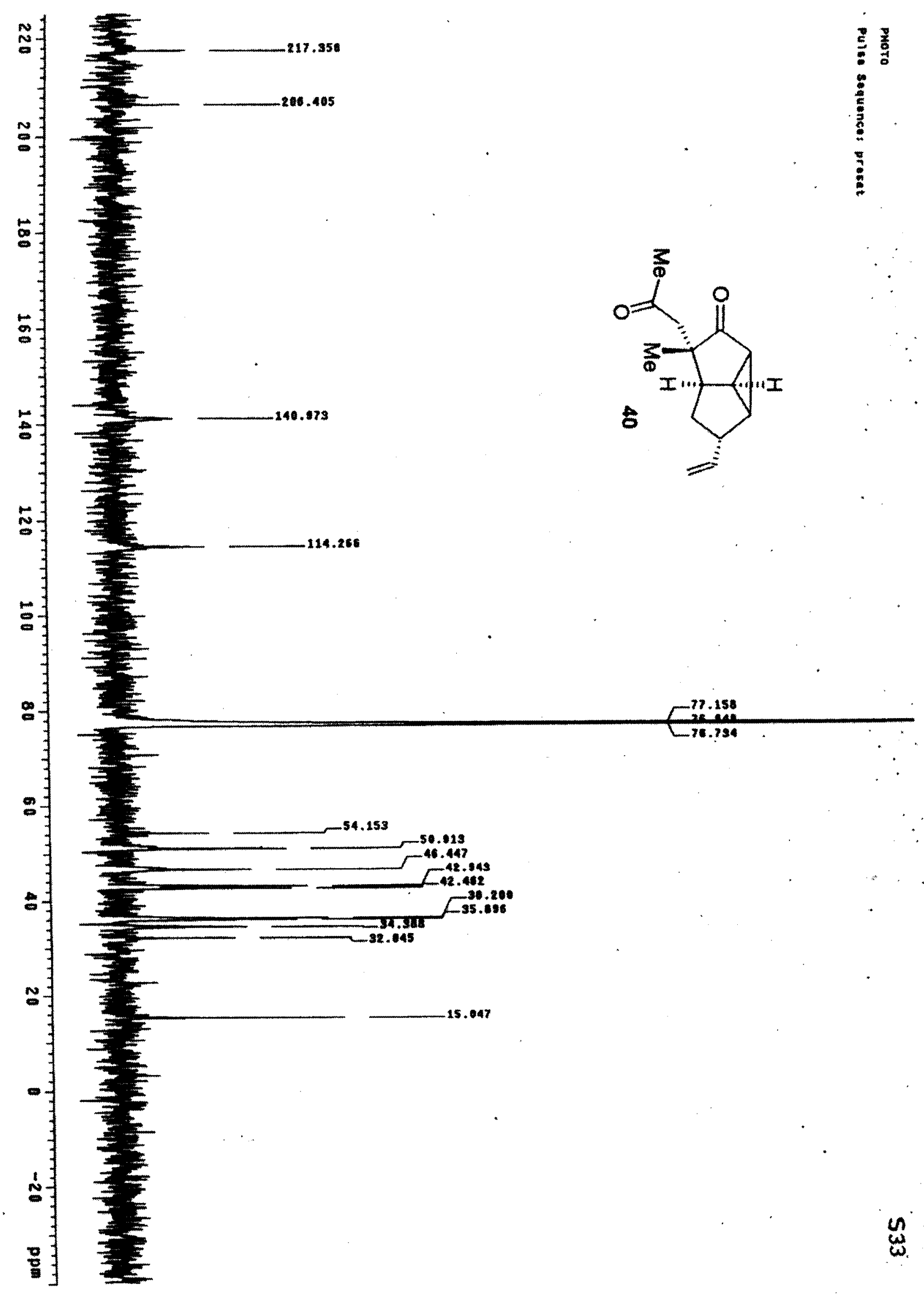

